\title{
A 13-Week Repeated Oral Dose Toxicity Study of ChondroT in Sprague-Dawley Rats
}

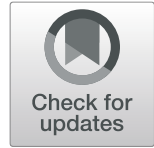

Jiwon Jeong ${ }^{1}$, Kiljoon Bae ${ }^{2}$, Jihoon $\mathrm{Kim}^{3}{ }^{3}$, Chanhun $\mathrm{Choi}^{3}$, Changsu $\mathrm{Na}^{3}$, Myeongkyu Park ${ }^{4}$, Youngran Kim${ }^{5}$, Chang-Seob $\mathrm{Seo}^{6}$ and Seon-Jong $\mathrm{Kim}^{3 *}$

\begin{abstract}
Background: ChondroT, a new herbal medication, consists of Angelica grosseserrata Maxim., Lonicera japonica Thunb., Angelica gigas Nakai, Clematis terniflora var. manshurica (Rupr.) Ohwi, and Phellodendron amurense Rupr. (6:4:4:4:3). Our previous studies have shown that ChondroT exhibits significant anti-arthritic and anti-inflammatory effects. In this study, we aimed to assess the toxicological safety assessment of ChondroT.

Methods: This study was designed to assess the safety of ChondroT after repeated oral administration. Male and female Sprague-Dawley rats were treated with ChondroT at oral doses of 0, 500, 1000, and $2000 \mathrm{mg} / \mathrm{kg}$ for 13 weeks. Mortality, clinical signs, body weight changes, food consumption, ophthalmological findings, urinalysis, hematological and blood-chemical parameters, necropsy findings, organ weights, and histological markers were recorded throughout the study period. Rats were also monitored for an additional 4 weeks to determine the recovery time.

Results: No death occurred and no significant changes in food consumption, ophthalmologic findings, and urinalysis were found. Although there were alterations in clinical signs, body weights, hematological parameters, blood-chemical parameters, necropsy findings, organ weights, and histological markers, they were not considered to be toxicologically significant.

Conclusions: The results suggest that the no-observed adverse effects level (NOAEL) was $2000 \mathrm{mg} / \mathrm{kg} /$ day for the test substance. ChondroT, a new complex herbal medication composed of five plants, can therefore be used safely at the NOAEL.
\end{abstract}

Keywords: ChondroT, 13-week repeated oral dose toxicity, 4-week recovery test, NOAEL

\section{Background}

Ganghwaljetongyeum (GHJTY) is a traditional Korean herbal medicine used to treat joint pain, restricted movement, fever, and swelling $[1,2]$. In a previous study, bioinformatics and experimental screening were employed to improve the efficacy and relevance of GHJTY as a pharmaceutical [3], thus creating ChondroT, which consists of Angelica grosseserrata Maxim., Lonicera japonica Thunb., Angelica gigas Nakai, Clematis terniflora var. mandshurica (Rupr.) Ohwi, and Phellodendron amurense Rupr. (6:4:4:4:3).

\footnotetext{
* Correspondence: mofoster@hanmail.net

${ }^{3}$ College of Korean Medicine, Dongshin University, 185 Geonjae-ro, Naju,

58245 Jeollanam-do, Republic of Korea

Full list of author information is available at the end of the article
}

ChondroT exerts chondroprotective effects and possesses multitarget mechanisms related to inflammation and arthritis [4-6]. In fact, the suppressive effect of ChondroT is greater than that of GHJT Y[7]. Moreover, ChondroT has shown therapeutic potential for the treatment of patients with hyperuricemia and gout [8]. Thus, it is currently undergoing clinical trials for approval from Ministry of Korean Food and Drug Safety [9].

Studies remain to be conducted on the toxicity of ChondroT. Although a 4-week repeated oral dose toxicity study had shown no adverse effects in Sprague-Dawley (SD) rats administered the maximum recommended dose of $2000 \mathrm{mg} / \mathrm{kg} / \mathrm{day}$ via oral gavage [10], that study was performed primarily to determine the dosage range for a subsequent 13-week study. Thus, information regarding

(c) The Author(s). 2019 Open Access This article is distributed under the terms of the Creative Commons Attribution 4.0 International License (http://creativecommons.org/licenses/by/4.0/), which permits unrestricted use, distribution, and reproduction in any medium, provided you give appropriate credit to the original author(s) and the source, provide a link to the Creative Commons license, and indicate if changes were made. The Creative Commons Public Domain Dedication waiver (http://creativecommons.org/publicdomain/zero/1.0/) applies to the data made available in this article, unless otherwise stated. 
the oral toxicity of ChondroT during the subchronic period is insufficient.

In this 13-week repeated oral administration study on SD rats, we aimed to elucidate the toxic effects of ChondroT, identify its target organs, and determine its no-observed-adverse-effect-level (NOAEL) in order to provide toxicological data for assessing the safety of ChondroT.

\section{Methods}

\section{Test facility}

This study was conducted in compliance with the principles of Good Laboratory Practice at Korea Testing \& Research Institute (KTR Hwasun) using the Korea Good Laboratory Practice (KGLP, Ministry of Food and Drug Safety Notification No. 2014-67, 2014-02-12) and OECD Principle of Good Laboratory Practice (ENV/MC/SHEM (98)17 as revised in 1997).

The study protocol was reviewed and approved (IAC2015-0797) by the Institutional Animal Care and Use Committee (IACUC) of KTR Hwasun based on the Animal Protection Act [Enforcement Date: 2015-01-20; No. 13023(2015-01-20, partial revision)] and the Laboratory Animal Act [Enforcement Date: 2013-07-30; No. 11987(2013-07-30, partial revision)].

The study was also conducted in accordance with the guideline for toxicity testing of pharmaceutical products by the Ministry of Food and Drug Safety (MFDS, Notification No. 2014-136, 2014-07-30).

\section{Animals}

SD rats (Crl:CD, Specific Pathogen Free (SPF); age, 5 weeks old) were purchased from Orient Bio Co. Ltd. (Seongnam-si, Gyeonggi Province, Republic of Korea). A total of 110 rats (body weight: males, 121.4-141.6 g; females, 111.1-129.2 g) were quarantined and allowed to acclimatize for approximately one week.

After examining body weight changes and general conditions of animals, those deemed healthy were selected for this study (50 males, 50 females). Environmental conditions in the animal facility were maintained at $22 \pm$ $3^{\circ} \mathrm{C}\left(20.5-23.27^{\circ} \mathrm{C}\right), 50 \pm 20 \%(46.0-65.6 \%)$ relative humidity, $10-20$ times/h ventilation frequency, $150-300$ Lux luminous intensity, and 12-h light/12-h dark cycle. There were no influenceable variations with these conditions.

Animals were given irradiation-sterilized pellet food (Rodent Diet 20 5053, Labdiet, USA) and ultrafiltration (reverse osmotic, R/O) water via a water bottle, ad libitum. The absence of contamination was confirmed by a periodical analysis of the food manufacturing facility and KTR Hwasun for the R/O water.

After group assignment, the remaining animals (five males, five females) were sacrificed using carbon dioxide
$\left(\mathrm{CO}_{2}\right)$ in accordance with the American Veterinary Medical Association (AVMA) guidelines.

\section{Group assignment and dosing}

After the acclimatization period, 100 healthy rats (6 weeks old; male 181.7-203.9 g, female 53.0-177.5 g) were randomly divided according to average weight and standard deviation. For dose selection, we considered the result of previously reported repeated toxicity study (Study No.: TBW-0064-15, 4 weeks repeated toxicity; 0, $500,1000,2000 \mathrm{mg} / \mathrm{kg}$ ) [10] where no significant toxicological changes were found at doses up to $2000 \mathrm{mg} / \mathrm{kg}$. The dose $2000 \mathrm{mg} / \mathrm{kg}$ was selected as the high (maximum) dose and two-fold intervals were used for the lower dose levels in the present 13-week repeated dose toxicity study; 1000 and $500 \mathrm{mg} / \mathrm{kg}$ were set as the intermediate and low (minimum) doses, respectively.

Study animals were divided into the groups listed in Table 1. Eighty rats were randomly divided into four groups (20 animals per group) for each dose (treatment group). Twenty rats were allocated to the control and high dose groups for the identification of any toxic effects, whether persistent or delayed, at 4 weeks postexposure (recovery group).

\section{Preparation of test substance and dosing}

ChondroT (Lot No. 501) was supplied from Jung-woo Co. (Asan, Korea). The five herbs were combined in a 6: 4:4:4:3 ratio (Table 2). ChondroT was prepared by carrying out water extraction once, using 10 -fold solvent at $100^{\circ} \mathrm{C}$ for $3 \mathrm{~h}$, and then filtering it (180 mesh). The water extract solution was concentrated using a continuous vacuum evaporator (approximately $55-60^{\circ} \mathrm{C}, 670$ $\mathrm{mmHg}$ ), and this was followed by vacuum drying using a vacuum drier $(720 \mathrm{mmHg})$ for $8 \mathrm{~h}$. The yield was approximately $29.4 \%$.

The ChondroT dried extract (light brown powder) was suspended in distilled water (D.W., Daihan Pharm Co., Ltd.) to achieve concentrations of 50,100, and $200 \mathrm{mg} /$ $\mathrm{mL}$ for treatment. The administration volume was 10 $\mathrm{mL} / \mathrm{kg}$ based on the most recently measured body weight. The test substance was administered once/day, 7 days/week, for 13 weeks by oral gavage using a stomach tube and was suspended using a magnetic stirrer during administration. The control group was administered vehicle (DW, Daihan Pharm Co., Ltd.).

\section{High-Performance Liquid Chromatography (HPLC) analysis}

Five marker components (chlorogenic acid, berberine chloride $(\mathrm{Cl})$, oxypeucedanin hydrate, decursin, and decursinol angelate) were purchased from Acros Organics (Pittsburgh, PA, USA), Shanghai Sunny Biotech (Shanghai, China), ChemFaces (Wuhan, China), and NPC Bio 
Table 1 Dosage groups used for the 13-week repeated dose oral toxicity study with SD rats

\begin{tabular}{|c|c|c|c|c|c|c|}
\hline \multirow[t]{2}{*}{ Group } & \multirow{2}{*}{$\begin{array}{l}\text { Dose } \\
\text { (mg/ } \\
\mathrm{kg} / \\
\text { day) }\end{array}$} & \multirow{2}{*}{$\begin{array}{l}\text { Administered } \\
\text { Fluid Volume } \\
(\mathrm{mL} / \mathrm{kg})\end{array}$} & \multirow[t]{2}{*}{ Week } & \multicolumn{3}{|c|}{ Number of rats $(n)^{*} / \operatorname{Sex}$} \\
\hline & & & & Male & Female & Total \\
\hline \multirow[t]{2}{*}{$\overline{\mathrm{G} 1}$} & 0 & 10 & 13 & 10(1101-1110) & 10(2101-2110) & 20 \\
\hline & & & $17^{\#}$ & $5(1111-1115)$ & $5(2111-2115)$ & 10 \\
\hline G2 & 500 & 10 & 13 & 10(1201-1210) & 10(2201-2210) & 20 \\
\hline G3 & 1000 & 10 & 13 & 10(1301-1310) & 10(2301-2310) & 20 \\
\hline \multirow[t]{2}{*}{ G4 } & 2000 & 10 & 13 & $10(1401-1410)$ & $10(2401-2410)$ & 20 \\
\hline & & & $17^{\#}$ & $5(1411-1415)$ & $5(2411-2415)$ & 10 \\
\hline
\end{tabular}

${ }^{*}$ : Objective numbers, ${ }^{\#}$ : Recovery group

Technology (Yeongi, Korea), respectively. Analytical method for quality control of ChondroT sample using HPLC was described in detail in previous studies $[5,6]$. In other words, the HPLC used for simultaneous analysis of the five marker components was the Shimadzu Prominence LC-20A Series (Shimadzu, Kyoto, Japan) coupled with photo-diode array (PDA) detector. A SunFire ${ }^{\mathrm{TM}} \mathrm{C}_{18}$ analytical column $(4.6 \times 250 \mathrm{~mm}, 5 \mu \mathrm{m}$; Waters, Milford, MA, USA) was used for the separation of the five marker components at a constant temperature of $40^{\circ} \mathrm{C}$. The mobile phase was eluted with distilled water (A) and acetonitrile (B), both containing $0.1 \%(\mathrm{v} / \mathrm{v})$ formic acid under the gradient elution mode. The parameters for the HPLC quantitative analysis were as follows: $0-30 \mathrm{~min}, 10-100 \%$ B; $30-40 \mathrm{~min}, 100 \% \mathrm{~B} ; 40-50 \mathrm{~min}, 100-10 \%$ B. The flow rate and injection volume were $1.0 \mathrm{~mL} / \mathrm{min}$ and $10 \mu \mathrm{L}$, respectively.

\section{Observations}

\section{Clinical signs}

All animals were observed daily before, during, and after oral treatment. Any treatment-related signs were individually recorded throughout the experimental period (13-week treatment and 4-week recovery period). In addition, mortality, development of clinical symptoms, and toxicity signs were recorded.

\section{Body weight}

Body weights of animals were measured on the day they were received, during group assignment, once per week, and the day before necropsy (13-week treatment and 4- week recovery period). Fasted weight was also measured on the day of necropsy to derive relative weight.

\section{Food consumption}

Food consumption was measured pre-dose and once per week for the 13-week treatment and 4-week recovery period. A weighed amount of food was placed in each cage and the amount remaining in each cage was measured the following day. Pre-dosing, food consumption was measured from group assignment to the first dosing day.

\section{Ophthalmic examination and urinalysis}

Ophthalmological examination and urinalysis were performed (five rats/sex/group) during the last week of treatment and the recovery period. Gross examination was performed followed by ophthalmological examination using mydriatic (Tropicamide 1\%, Alcon, Belgium) and fundus camera (Genesis, Kowa, Japan). Urinalysis (i.e., appearance, volume, specific gravity, $\mathrm{pH}$, protein, glucose, ketone body, bilirubin, urobilinogen, nitrite, blood, leukocyte, and urinary sediments) was performed with urine collected from a metabolic cage. Urinalysis items were analyzed using an automatic tester (CliniTek 500, Siemens, Germany), urine stick (Multistix 10 SG, Siemens, Germany) and a microscope (Leica, Germany).

\section{Hematology and serum biochemistry}

All animals were fasted overnight before blood sampling. Blood samples were drawn from the aorta under anesthesia and transferred to CBC bottle (EDTA K2, $\mathrm{BD}, \mathrm{USA}$ ) and vacutainer (9NC Sodium citrate, BD,

Table 2 Composition of ChondroT and the used parts of five herbs

\begin{tabular}{|c|c|c|c|c|c|}
\hline Latin name & Scientific name & Family & Used part & Rate & Source \\
\hline Osterici Radix & Ostericum koreanum Maximowicz & Umbelliferae & Root & 6 & Korea \\
\hline Angelicae Gigantis Radix & Angelica gigas Nakai & Umbelliferae & Root & 4 & Korea \\
\hline Clematidis Radix & Clematis manshurica Ruprecht & Ranunculaceae & Root & 4 & China \\
\hline Lonicerae Folium & Lonicera japonica Thunberg & Caprifoliaceae & Leaf & 4 & China \\
\hline Phellodendri Cortex & Phellodendron amurense Ruprecht & Rutaceae & Tree bark & 3 & China \\
\hline
\end{tabular}


USA) for hematological and coagulation tests, respectively. For the coagulation test, plasma was separated by centrifugation $\left(3000 \mathrm{rpm}, 4^{\circ} \mathrm{C}, 10 \mathrm{~min}\right)$. The hematological parameters, total erythrocyte count (red blood cells, RBC), hemoglobin concentration (HGB), hematocrit $(\mathrm{HCT})$, mean corpuscular volume (MCV), mean corpuscular hemoglobin $(\mathrm{MCH})$, mean corpuscular hemoglobin concentration (MCHC), reticulocyte (Retic), platelet count (PLT), total leucocyte count (white blood cells, WBC), WBC differential count (neutrophils, lymphocytes, monocytes, eosinophils, and basophils), prothrombin time (PT), and activated partial thromboplastin time (APTT) were measured using a hematological auto-analyzer (ADVIA 2120i, Siemens, USA) and coagulation analyzer (ACL 7000, Instrumentation Laboratory, USA).

The remaining samples, except blood samples for hematological and coagulation tests, were placed in tubes without an anticoagulant for serum separation. The tubes were kept at room temperature and serum was separated by centrifugation $\left(3000 \mathrm{rpm}, 4^{\circ} \mathrm{C}, 10 \mathrm{~min}\right)$. The biochemical parameters, total protein, albumin, albumin/globulin (A/G) ratio, total bilirubin (T-Bil; Hanlab Labmaster, Korea), alkaline phosphatase (ALP; Denka Seiken, Japan), aspartate aminotransferase (AST; Denka Seiken, Japan), alanine aminotransferase (ALT; Denka Seiken, Japan), creatinine (CREA; Hanlab Labmaster, Korea), blood urea nitrogen (BUN; Hanlab Labmaster, Korea), total cholesterol (T-CHO; Kyowa, Japan), triglyceride (TG; Kyowa, Japan), glucose (GLU; Denka Seiken, Japan), calcium (CA; Denka Seiken, Japan), inorganic phosphorus (IP; Hanlab Labmaster, Korea), creatine kinase (CK; Denka Seiken, Japan), sodium $\left(\mathrm{Na}^{+}\right.$; Canon, Japan), potassium $\left(\mathrm{K}^{+}\right.$; Canon, Japan), and chloride $\left(\mathrm{Cl}^{-}\right.$; Canon, Japan) were analyzed using an autoanalyzer (TBA-120FR, Toshiba, Japan).

\section{Gross finding at necropsy}

On the day scheduled for necropsy, all animals were anaesthetized by isoflurane inhalation (Forane, JW Pharmaceutical, Korea) followed by blood sampling. Animals were exsanguinated from the posterior vena cava and aorta prior to necropsy. Macroscopic examinations of the external surface, all orifices, all internal organs of the head, thoracic and abdominal cavities were performed on the dead animals.

\section{Organ weight}

When all animals were sacrificed, absolute organ weights were measured and relative organ weights (organ weight to fasted body weight ratios before necropsy, \%) were calculated for the following organs: brain, pituitary gland, heart, lung, liver, spleen, kidney $(*)$, adrenal gland $(*)$, testis $\left(^{*}\right)$, epididymis $\left(^{*}\right)$, ovary $\left(^{*}\right)$, uterus, thymus, prostate gland, and submandibular gland. The bilateral organs (*) were respectively measured and the measured weight was summed.

\section{Histopathological examination}

Tissues were fixed in neutral buffered $10 \%$ formalin, Bouin's fixative (for the testes/epididymides) and Davidson's solution (for the eyes with the Harderian gland). Tissues representing the liver, kidney, adrenal gland, heart, lung, brain (pituitary gland), spleen, prostate gland (with seminal vesicle and coagulating glands), testes, epididymides, ovary, uterus, vagina, tongue, trachea, esophagus, thymus, thyroid gland (with parathyroid gland), stomach, intestine, eye (with the Harderian gland), urinary bladder, submandibular gland, skin, pancreas, sternum, mammary gland, spinal cord, femur, mesenteric lymph node, sciatic nerve, and skeletal muscle from the control and high dose groups were embedded in paraffin, sectioned, stained with hematoxylin and eosin (H\&E stain), and examined with a microscope. Necropsy was also performed with animals (No.1104, 1204, 1308, 2302).

\section{Statistical Analysis}

Data are presented as mean \pm standard deviation (S.D.) for body weight, food consumption, organ weight, hematology, and biochemistry and were analyzed by SPSS software (ver. 19.0). The Leven's test was performed to derive the homogeneity of variance and one way ANOVA was performed to determine the significant differences between groups. If there were no significant differences, an additional analysis was not performed; however, if a significant difference was confirmed, posthoc test was used according to the result of variance homogeneity (homogeneity; Scheffe test, heterogeneity; Dunnett's T3 test). In the recovery group, data analysis was performed using independent $t$-test. A $p$ value < 0.05 was considered significant.

\section{Results \\ Quality assessment of the five marker components in ChondroT Sample}

Using the established HPLC method, simultaneous determination was conducted to evaluate the 13-week treatment of ChondroT sample. The five marker components (chlorogenic acid, berberine $\mathrm{Cl}$, oxypeucedanin hydrate, decursin, and decursinol angelate) were eluted within $30 \mathrm{~min}$ and the retention times of these components were $8.94,10.80,15.95,26.02$, and $26.24 \mathrm{~min}$, respectively (Fig. 1). The coefficient of determination for the calibration curve of the five components was $\geq$ 0.9996, showing a good linearity. The amounts of the five marker components ranged between 0.81 and 5.46 $\mathrm{mg} / \mathrm{g}$ (Table 3). 
(A)
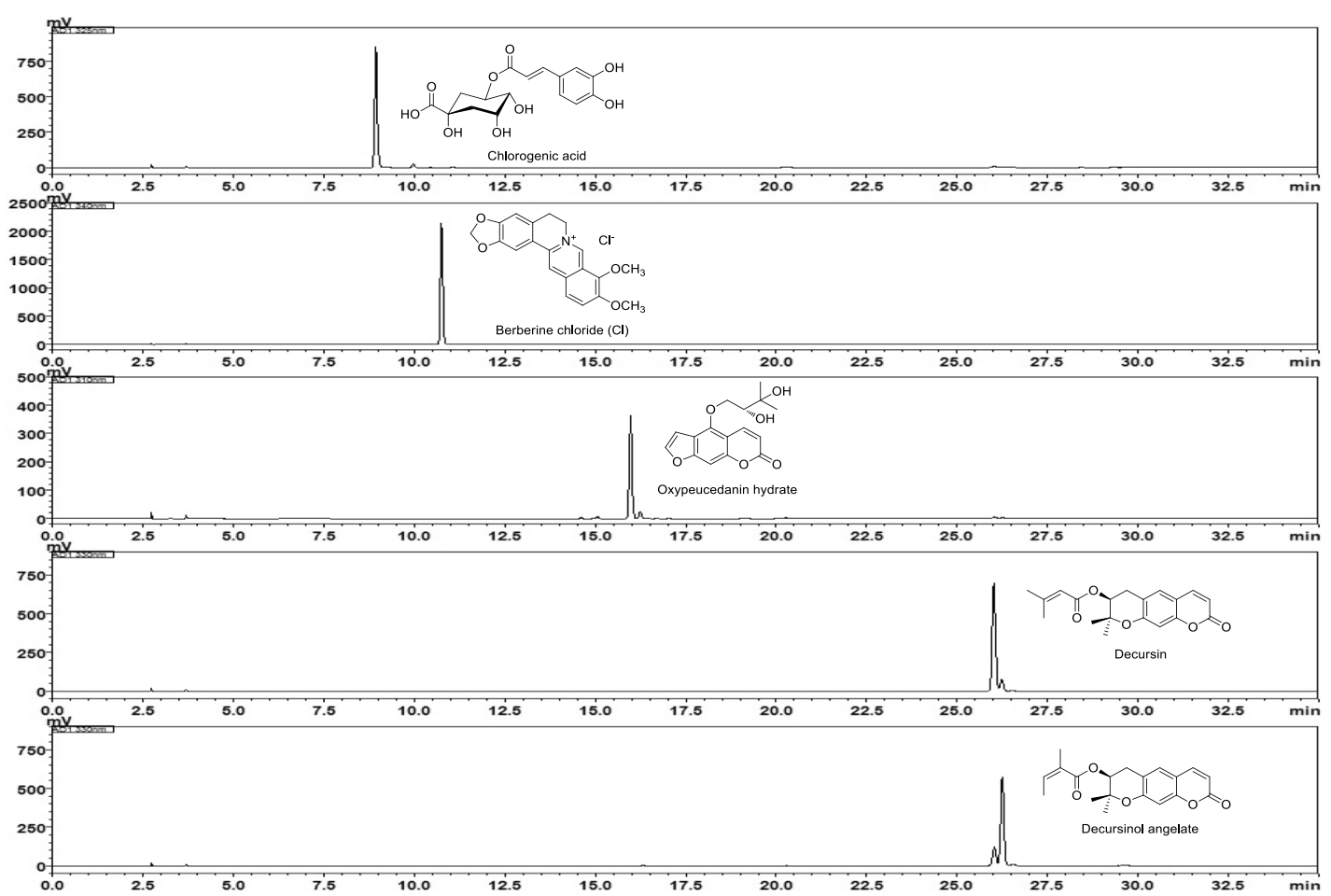

(B)
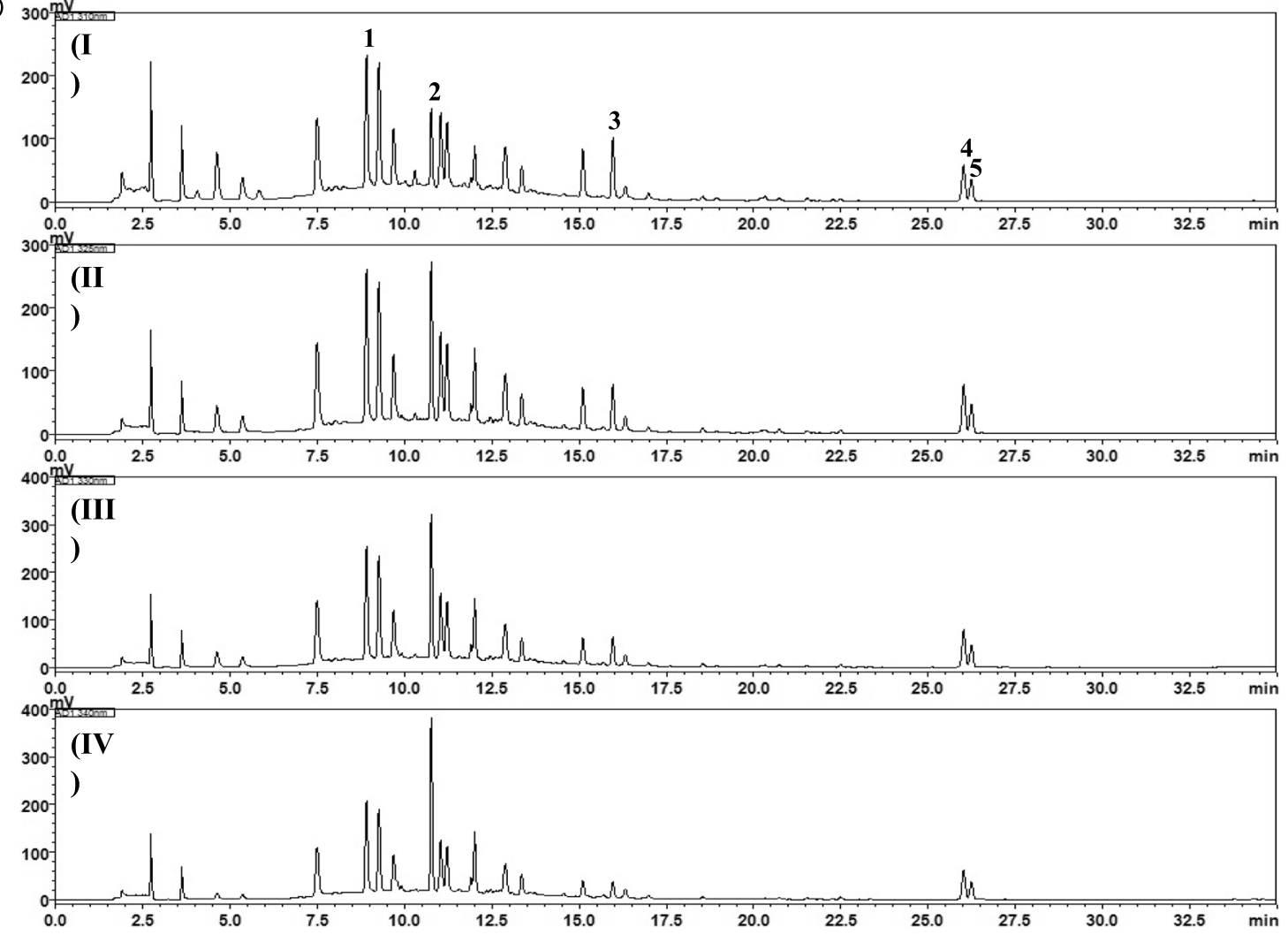

Fig. 1 Typical HPLC-PDA chromatograms of each standard compound (a) and ChondroT sample at 310 (I), 325 (II), 330 (III), and 340 (IV) nm (b). Chlorogenic acid (1), Berberine Cl (2), oxypeucedanin hydrate (3), decursin (4), and decursinol angelate (5) 
Table 3 Parameters for quantitative analysis and amount of five marker components in ChondroT sample

\begin{tabular}{llllll}
\hline Compound & Detection wavelength $(\mathrm{nm})$ & $\begin{array}{l}\text { Linear range } \\
(\mu \mathrm{g} / \mathrm{mL})\end{array}$ & Regression equation ${ }^{\mathrm{a}}$ & $r^{2}$ & Amount $(\mathrm{mg} / \mathrm{g})$ \\
\hline Chlorogenic acid & 325 & $1.56-100.00$ & $y=30429.94 x-42881.66$ & 0.9996 & 5.46 \\
Berberine Cl & 340 & $0.78-50.00$ & $y=81886.13 x+16338.31$ & 0.9999 & 1.87 \\
Oxypeucedanin hydrate & 310 & $1.56-100.00$ & $y=26221.17 x+5076.06$ & 1.0000 & 2.03 \\
Decursin & 330 & $0.78-50.00$ & $y=37915.21 x+52952.92$ & 1.0000 & 1.09 \\
Decursinol angelate & 330 & $0.78-50.00$ & $y=28967.64 x+29015.53$ & 1.0000 & 0.81 \\
\hline
\end{tabular}

\section{Mortality and clinical signs}

During the experimental period, treatment-related moribund, dead animals, and clinical signs were not observed for both the sexes in the control and treatment groups. However, loss of fur in posterior neck from day 12 to 91 and abdomen from day 25 to 91 (one female at middle dose) and a nodule (slightly hard with an egg-shape) from day 63 to 91 (one female administered the middle dose) were clinical signs observed. Salivation was transiently or intermittently observed in both the sexes when the high dose was administered (Table 4).

\section{Body weight and food consumption}

A gradual increase in body weight of males was observed over the treatment period, with significant differences $(p<0.05)$ at weeks 10 (ANOVA test: $\mathrm{F}$ value, $3.345 ; \mathrm{p}$ value, 0.027 ; post-hoc test: Scheffe $\mathrm{p}$ value, 0.041 ) and 11 (ANOVA test: $F$ value, 3.615; $\mathrm{p}$ value, 0.020; post-hoc test: Scheffe $p$ value, 0.036) for animals administered the $2000 \mathrm{mg} / \mathrm{kg}$ dose. No significant differences were found for females among the groups (Fig. 2).
There was no significant difference in food consumption between the treatment groups and control group for both the sexes (Fig. 3).

\section{Ophthalmological examination and urinalysis}

There were no treatment-related changes during the treatment and recovery periods for the different dosage groups.

\section{Hematology and serum biochemistry}

There was no significant difference in the hematological items over the treatment period. However, some items displayed significant differences in the recovery period. There was a significant increase in mono (Levene's test: F value, 1.884; $p$ value, 0.212 ; independent $t$-test: $p$ value, 0.049 ) for males and neut (Levene's test: F value, 0.007; $p$ value, 0.937 , independent $t$-test: $p$ value, 0.036$)$ and baso (Levene's test: $\mathrm{F}$ value, 0.099, $p$ value: 0.762; independent $t$-test: $p$ value, 0.020$)$ for females administered the $2000 \mathrm{mg} / \mathrm{kg}$ dose, and a significant decrease in Lymph (Levene's test: $\mathrm{F}$ value, $0.821 ; p$ value: 0.395 , independent $t$-test: $p$ value, 0.038$)$ for females

Table 4 Clinical signs observed in the 13-week repeated oral dose toxicity study with SD rats

\begin{tabular}{|c|c|c|c|c|c|c|c|c|c|c|c|c|c|c|c|c|c|c|c|c|c|}
\hline \multirow{2}{*}{$\begin{array}{l}\text { Group } \\
\text { (Dose)* }\end{array}$} & \multirow[t]{2}{*}{ Week } & \multirow[t]{2}{*}{ Sex } & \multirow{2}{*}{$\begin{array}{l}\text { Number } \\
\text { of rats }\end{array}$} & \multicolumn{17}{|c|}{ Weeks / Number of rats observed clinical signs } & \multirow{2}{*}{$\begin{array}{l}\text { Mortality } \\
\text { (dead/total) }\end{array}$} \\
\hline & & & & 1 & 2 & 3 & 4 & 5 & 6 & 7 & 8 & 9 & 10 & 11 & 12 & 13 & 14 & 15 & 16 & 17 & \\
\hline \multirow[t]{4}{*}{$\overline{G 1(0)}$} & 13 & Male & 10 & 0 & 0 & 0 & 0 & 0 & 0 & 0 & 0 & 0 & 0 & 0 & 0 & 0 & - & - & - & - & $0 \%$ \\
\hline & & Female & 10 & 0 & 0 & 0 & 0 & 0 & 0 & 0 & 0 & 0 & 0 & 0 & 0 & 0 & - & - & - & - & $0 \%$ \\
\hline & $17^{\#}$ & Male & 5 & 0 & 0 & 0 & 0 & 0 & 0 & 0 & 0 & 0 & 0 & 0 & 0 & 0 & 0 & 0 & 0 & 0 & $0 \%$ \\
\hline & & Female & 5 & 0 & 0 & 0 & 0 & 0 & 0 & 0 & 0 & 0 & 0 & 0 & 0 & 0 & 0 & 0 & 0 & 0 & $0 \%$ \\
\hline \multirow[t]{2}{*}{ G2 (500) } & 13 & Male & 10 & 0 & 0 & 0 & 0 & 0 & 0 & 0 & 0 & 0 & 0 & 0 & 0 & 0 & - & - & - & - & $0 \%$ \\
\hline & & Female & 10 & 0 & $1^{* *}$ & $1^{* *}$ & $1^{* *}$ & $1^{* *}$ & $1^{* *}$ & $1^{\# \#}$ & $1^{\# \#}$ & $2^{\# \#}$ & $2^{\# \#}$ & $2^{\# \#}$ & $2^{\# \#}$ & $2^{\# \#}$ & - & - & - & - & $0 \%$ \\
\hline \multirow[t]{2}{*}{ G3 (1000) } & 13 & Male & 10 & 0 & 0 & 0 & 0 & 0 & 0 & 0 & 0 & 0 & 0 & 0 & 0 & 0 & - & - & - & - & $0 \%$ \\
\hline & & Female & 10 & 0 & 0 & 0 & 0 & 0 & 0 & 0 & 0 & 0 & 0 & 0 & 0 & 0 & - & - & - & - & $0 \%$ \\
\hline \multirow[t]{4}{*}{ G4 (2000) } & 13 & Male & 10 & 0 & 0 & 0 & 0 & 0 & 0 & 0 & 0 & 0 & 0 & 0 & 0 & 0 & - & - & - & - & $0 \%$ \\
\hline & & Female & 10 & 0 & 0 & 0 & 0 & 0 & 0 & 0 & 0 & 0 & 0 & 0 & 0 & 0 & - & - & - & - & $0 \%$ \\
\hline & $17^{\#}$ & Male & 5 & 0 & 0 & 0 & 0 & 0 & 0 & 0 & 0 & 0 & 0 & 0 & 0 & 0 & 0 & 0 & 0 & 0 & $0 \%$ \\
\hline & & Female & 5 & 0 & 0 & 0 & 0 & 0 & 0 & 0 & 0 & 0 & 0 & 0 & 0 & 0 & 0 & 0 & 0 & 0 & $0 \%$ \\
\hline
\end{tabular}

${ }^{*}: \mathrm{mg} / \mathrm{kg},-$ : not applicable, ${ }^{\#}:$ Recovery group ${ }^{* *}$ : Loss of fur of posterior neck and abdomen(No.2308), ${ }^{\# \#}$ : Loss of fur of posterior neck and abdomen(No.2308), Slightly hard egg-shaped nodule of right neck(No. 2302) 


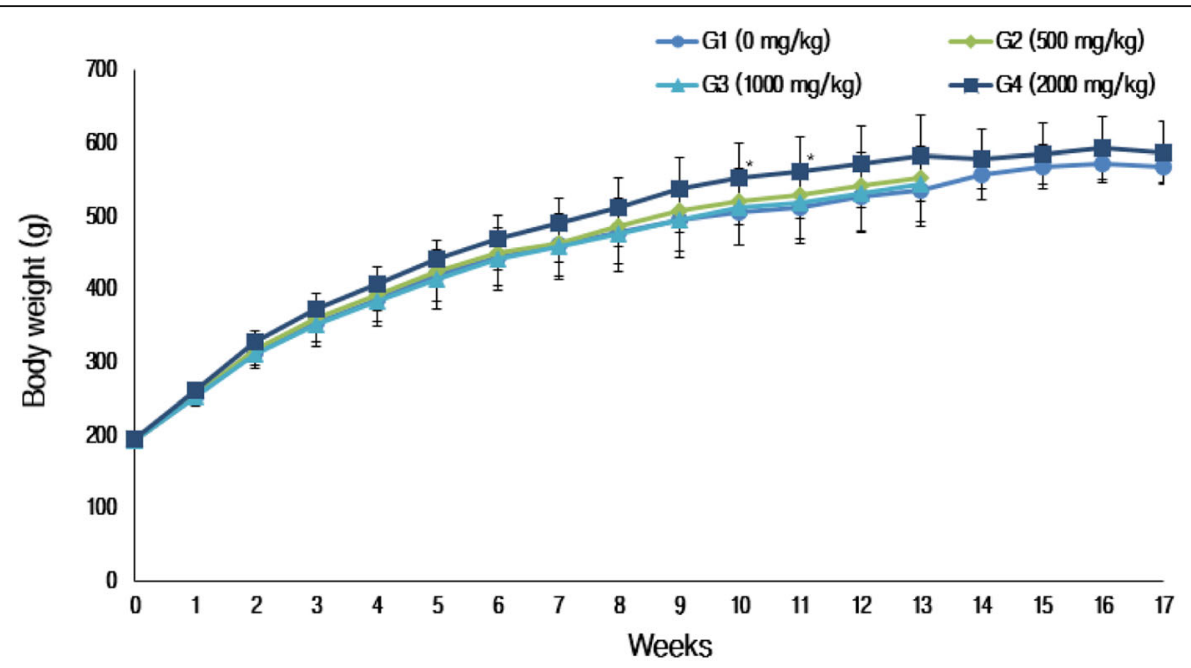

(A) Male

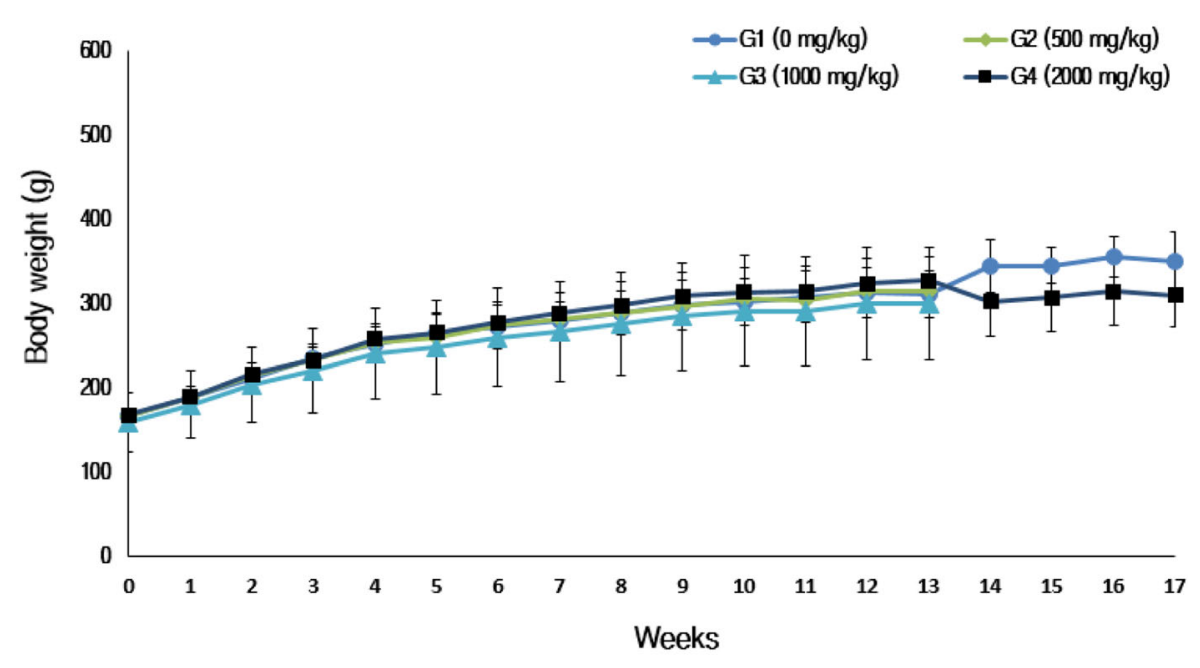

(B) Female

Fig. 2 Body weights of the rats used in the experiment

administered the $2000 \mathrm{mg} / \mathrm{kg}$ dose. Samples with a blood clot were excluded from the statistical analysis (treatment group, one male administered $2000 \mathrm{mg} / \mathrm{kg}$; recovery group, one male and one female in the control group; Table 5).

For serum biochemistry items, significant increases were found for sodium (ANOVA test: $\mathrm{F}$ value, 4.475; $p$ value, 0.009 ; post-hoc test: Scheffe $p$ value, 0.026 ) in males and triglycerides (ANOVA test: $\mathrm{F}$ value, 3.443, $p$ value, 0.027 , post-hoc test, Scheffe $p$ value, 0.047 ) in females administered $2000 \mathrm{mg} / \mathrm{kg}$. In the recovery group, no significant changes were found for both the sexes when administered $2000 \mathrm{mg} / \mathrm{kg}$ (Table 6).

\section{Gross finding at necropsy}

At the end of treatment, there were no treatmentrelated gross findings in the treatment groups over the 13-week treatment period and 4-week recovery period. However, the following gross findings were observed in the treatment group: reduced size of the left testis in one male in the control group, yellowish nodule on the prostate gland of one male in the low dose group and cysts and mass $(3.0 \times 4.5 \times 3.0 \mathrm{~cm})$ in the right submandibular region in one female administered the middle dose.

\section{Organ weight}

For absolute organ weight in the treatment group, there was a significant increase in the weight of the heart (low 


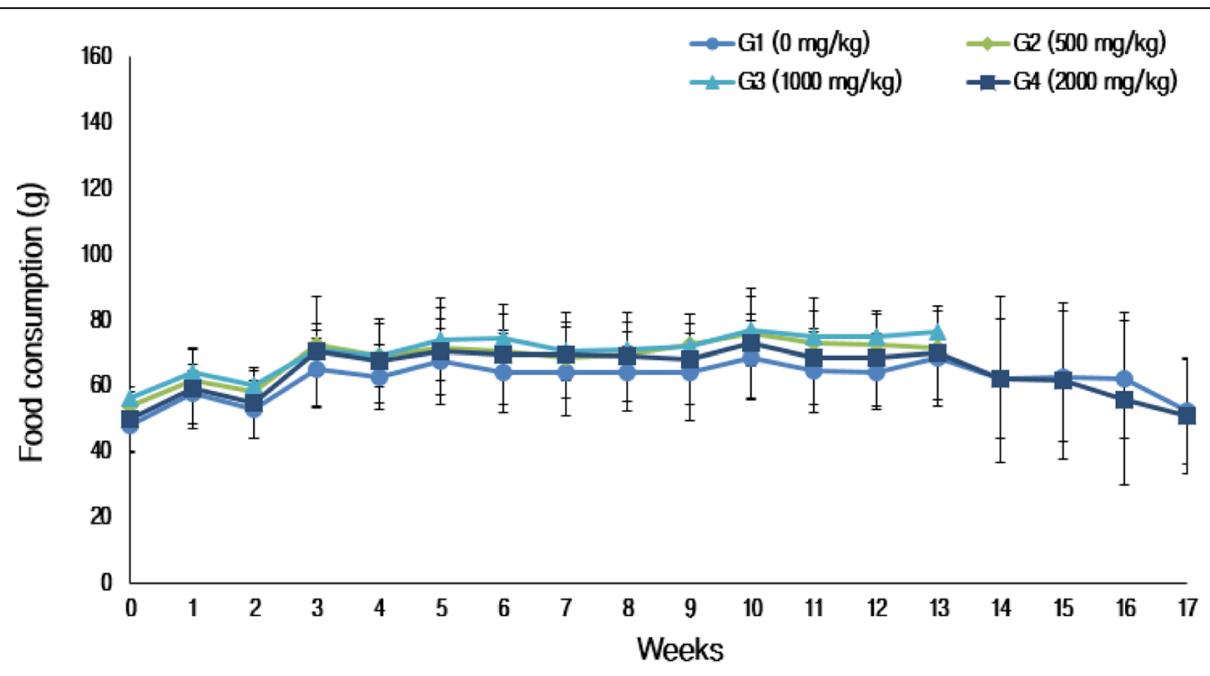

(A) Male

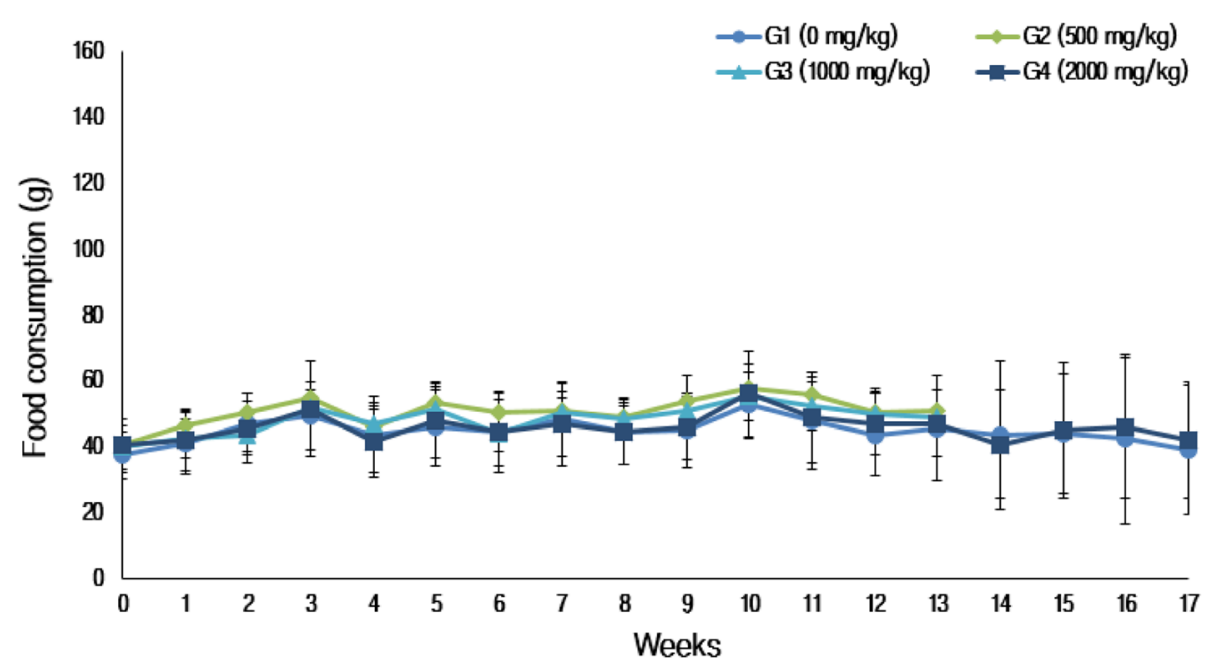

(B) Female

Fig. 3 Food consumption of the rats used in the experiment

dose, ANOVA test: F value, 6.205; p value, 0.002; posthoc test: Scheffe $p$ value, 0.038), liver (high dose, ANOVA test: $\mathrm{F}$ value, $4.273 ; p$ value, 0.011 ; post-hoc test: Scheffe $p$ value, 0.016) and lung (high dose, ANOVA test: $\mathrm{F}$ value, $4.559 ; p$ value, 0.008 ; post-hoc test, Scheffe $p$ value, 0.021 ) of males; these changes did not resemble that of relative organ weight. For relative organ weight, a significant decrease was found for the brain (high dose, ANOVA test: $\mathrm{F}$ value, $4.248 ; p$ value, 0.11 ; post-hoc test : Scheffe $p$ value, 0.018 ) of a male. There were no significant changes in the organ weight of females in the different treatment groups.

In the recovery group, there was a significant increase in the absolute organ weight of the thymus (high dose,
Levene's test: $\mathrm{F}$ value, $0.469 ; p$ value, 0.513 ; independent $t$-test, $p$ value, 0.013 ) of males and a significant decrease for that of the kidney (bilateral weight, high dose, Levene's test: $\mathrm{F}$ value, $4.007 ; p$ value, 0.080 ; independent $t$-test: $p$ value, 0.029$)$ and brain (high dose, Levene's test: F value, $0.063 ; p$ value, 0.808 ; independent $t$-test: $p$ value, 0.021) of females. Similarly, a significant decrease in relative organ weight was found for the testis (bilateral weight, high dose, Levene's test: $\mathrm{F}$ value, $1.281 ; p$ value, 0.291 ; independent $t$-test: $p$ value, 0.040 ).

\section{Histopathological examination}

The following histopathological lesions were observed in the high dose treatment group: inflammatory cell foci in 
Table $\mathbf{5}$ Hematological parameters

\begin{tabular}{|c|c|c|c|c|c|c|c|}
\hline \multirow[t]{2}{*}{ Parameters } & \multirow{2}{*}{$\begin{array}{l}\text { Group(Dose) } \\
\text { Sex/Week }\end{array}$} & \multicolumn{2}{|l|}{ G1(0) } & \multirow{2}{*}{$\begin{array}{l}\text { G2(500) } \\
13 \text { week }\end{array}$} & \multirow{2}{*}{$\begin{array}{l}\text { G3(1000) } \\
\text { 13week }{ }^{\# \#}\end{array}$} & \multicolumn{2}{|l|}{ G4(2000) } \\
\hline & & 13 week & 17 week $^{\#, * *}$ & & & 13 week $^{* *}$ & 17week ${ }^{\#}$ \\
\hline \multirow[t]{2}{*}{ Total leucocyte count $\left(10^{3}\right.$ cells $\left./ \mu \mathrm{L}\right)$} & Male & $5.09 \pm 1.38$ & $6.55 \pm 2.37$ & $5.39 \pm 1.13$ & $6.15 \pm 2.13$ & $6.27 \pm 3.02$ & $5.86 \pm 1.39$ \\
\hline & Female & $3.18 \pm 0.56$ & $3.00 \pm 1.07$ & $2.66 \pm 0.80$ & $5.10 \pm 5.41$ & $4.16 \pm 0.66$ & $2.89 \pm 1.08$ \\
\hline \multirow[t]{2}{*}{ Total erythrocyte count $\left(10^{6} \mathrm{cell} s / \mu \mathrm{L}\right)$} & Male & $8.44 \pm 0.33$ & $7.97 \pm 0.48$ & $8.38 \pm 0.21$ & $8.16 \pm 0.79$ & $8.16 \pm 0.94$ & $8.17 \pm 0.35$ \\
\hline & Female & $7.78 \pm 0.35$ & $7.24 \pm 0.10$ & $7.53 \pm 0.34$ & $7.55 \pm 0.45$ & $7.45 \pm 0.24$ & $7.30 \pm 0.15$ \\
\hline \multirow[t]{2}{*}{ Hemoglobin concentration (g/dL) } & Male & $14.6 \pm 0.7$ & $14.0 \pm 0.7$ & $14.4 \pm 0.4$ & $14.5 \pm 1.2$ & $14.2 \pm 1.4$ & $14.3 \pm 0.4$ \\
\hline & Female & $14.2 \pm 0.6$ & $13.5 \pm 0.3$ & $13.8 \pm 0.6$ & $13.8 \pm 0.8$ & $13.7 \pm 0.4$ & $13.8 \pm 0.3$ \\
\hline \multirow[t]{2}{*}{ Hematocrit(\%) } & Male & $42.2 \pm 1.7$ & $40.1 \pm 2.0$ & $42.1 \pm 1.0$ & $42.0 \pm 4.1$ & $41.0 \pm 4.1$ & $41.0 \pm 1.1$ \\
\hline & Female & $41.1 \pm 1.7$ & $38.6 \pm 0.5$ & $40.0 \pm 1.6$ & $40.1 \pm 1.9$ & $39.5 \pm 0.9$ & $39.4 \pm 0.9$ \\
\hline \multirow[t]{2}{*}{ Mean corpuscular volume (fL) } & Male & $50.0 \pm 1.5$ & $50.3 \pm 0.9$ & $50.3 \pm 1.6$ & $51.5 \pm 1.3$ & $50.4 \pm 1.4$ & $50.3 \pm 1.5$ \\
\hline & Female & $52.9 \pm 1.4$ & $53.3 \pm 0.5$ & $53.2 \pm 1.5$ & $53.1 \pm 1.4$ & $53.2 \pm 2.0$ & $54.1 \pm 1.0$ \\
\hline \multirow[t]{2}{*}{ Mean corpuscular hemoglobin (pg) } & Male & $17.2 \pm 0.6$ & $17.6 \pm 0.3$ & $17.2 \pm 0.6$ & $17.8 \pm 0.5$ & $17.4 \pm 0.6$ & $17.5 \pm 0.6$ \\
\hline & Female & $18.3 \pm 0.4$ & $18.7 \pm 0.4$ & $18.4 \pm 0.7$ & $18.2 \pm 0.5$ & $18.4 \pm 0.7$ & $18.9 \pm 0.1$ \\
\hline \multirow[t]{2}{*}{ Mean corpuscular hemoglobin concentration(g/dL) } & Male & $34.5 \pm 0.5$ & $35.0 \pm 0.5$ & $34.2 \pm 0.4$ & $34.5 \pm 0.6$ & $34.6 \pm 0.5$ & $34.9 \pm 0.4$ \\
\hline & Female & $34.6 \pm 0.3$ & $35.1 \pm 0.7$ & $34.6 \pm 0.6$ & $34.4 \pm 0.4$ & $34.6 \pm 0.4$ & $35.0 \pm 0.5$ \\
\hline \multirow[t]{2}{*}{ Reticulocyte $\left(10^{9} \mathrm{cells} / \mu \mathrm{L}\right)$} & Male & $155.3 \pm 45.7$ & $169.5 \pm 60.4$ & $164.2 \pm 34.1$ & $160.0 \pm 32.8$ & $200.1 \pm 95.6$ & $184.8 \pm 19.0$ \\
\hline & Female & $150.4 \pm 40.2$ & $172.6 \pm 34.6$ & $142.1 \pm 29.5$ & $176.4 \pm 72.4$ & $179.2 \pm 31.4$ & $146.6 \pm 26.4$ \\
\hline \multirow[t]{2}{*}{ Reticulocyte(\%) } & Male & $1.84 \pm 0.53$ & $2.14 \pm 0.83$ & $1.96 \pm 0.32$ & $1.95 \pm 0.32$ & $2.43 \pm 1.03$ & $2.26 \pm 0.21$ \\
\hline & Female & $1.94 \pm 0.51$ & $2.39 \pm 0.51$ & $1.89 \pm 0.37$ & $2.37 \pm 1.10$ & $2.41 \pm 0.45$ & $2.01 \pm 0.34$ \\
\hline \multirow[t]{2}{*}{ Platelet $\left(10^{3}\right.$ cells $\left./ \mu \mathrm{L}\right)$} & Male & $1041.3 \pm 142.1$ & $830.0 \pm 431.1$ & $973.9 \pm 73.6$ & $849.6 \pm 306.5$ & $819.6 \pm 452.8$ & $1035.6 \pm 70.1$ \\
\hline & Female & $967.6 \pm 68.5$ & $741.6 \pm 402.8$ & $844.3 \pm 300.9$ & $1008.5 \pm 99.2$ & $969.0 \pm 85.8$ & $1006.8 \pm 99.1$ \\
\hline \multirow[t]{2}{*}{ Prothrombin time(sec) } & Male & $13.6 \pm 0.8$ & $13.1 \pm 0.4$ & $14.5 \pm 1.1$ & $14.9 \pm 1.6$ & $14.0 \pm 1.9$ & $12.7 \pm 0.4$ \\
\hline & Female & $12.6 \pm 0.4$ & $13.4 \pm 1.9$ & $12.4 \pm 0.3$ & $12.4 \pm 0.4$ & $12.3 \pm 0.3$ & $12.9 \pm 0.2$ \\
\hline \multirow[t]{2}{*}{ Activated partial thromboplastin time(sec) } & Male & $17.7 \pm 1.7$ & $17.7 \pm 2.6$ & $20.1 \pm 1.7$ & $19.4 \pm 1.9$ & $19.0 \pm 3.2$ & $15.9 \pm 2.8$ \\
\hline & Female & $14.6 \pm 1.4$ & $14.8 \pm 3.6$ & $14.8 \pm 1.2$ & $14.4 \pm 1.5$ & $14.1 \pm 1.6$ & $16.5 \pm 2.0$ \\
\hline \multirow[t]{2}{*}{ Neutrophils(\%) } & Male & $21.2 \pm 10.0$ & $16.2 \pm 6.9$ & $20.4 \pm 6.4$ & $18.9 \pm 6.4$ & $17.9 \pm 4.4$ & $17.8 \pm 3.2$ \\
\hline & Female & $19.9 \pm 7.6$ & $16.4 \pm 2.8$ & $15.7 \pm 4.8$ & $26.4 \pm 16.7$ & $15.3 \pm 4.3$ & $22.3 \pm 3.1^{\dagger}$ \\
\hline \multirow[t]{2}{*}{ Lymphocytes(\%) } & Male & $73.1 \pm 11.3$ & $78.2 \pm 7.8$ & $73.1 \pm 7.3$ & $76.3 \pm 7.5$ & $76.9 \pm 5.0$ & $75.7 \pm 4.2$ \\
\hline & Female & $73.0 \pm 7.7$ & $76.5 \pm 3.3$ & $78.3 \pm 5.3$ & $67.1 \pm 15.9$ & $79.2 \pm 5.1$ & $68.5 \pm 4.9^{\dagger}$ \\
\hline \multirow[t]{2}{*}{ Monocytes(\%) } & Male & $2.2 \pm 1.0$ & $1.6 \pm 0.2$ & $2.4 \pm 0.5$ & $1.8 \pm 0.7$ & $2.2 \pm 1.1$ & $2.1 \pm 0.4^{\dagger}$ \\
\hline & Female & $2.4 \pm 0.3$ & $2.1 \pm 0.7$ & $1.7 \pm 0.8$ & $2.1 \pm 0.5$ & $1.8 \pm 0.5$ & $1.9 \pm 0.5$ \\
\hline \multirow[t]{2}{*}{ Eosinophils(\%) } & Male & $1.9 \pm 0.8$ & $2.8 \pm 1.2$ & $2.0 \pm 1.0$ & $1.5 \pm 0.7$ & $1.6 \pm 0.4$ & $3.5 \pm 0.7$ \\
\hline & Female & $3.0 \pm 1.0$ & $4.0 \pm 1.7$ & $3.0 \pm 1.6$ & $3.3 \pm 1.6$ & $2.3 \pm 0.6$ & $6.6 \pm 3.1$ \\
\hline \multirow[t]{2}{*}{ Basophils(\%) } & Male & $0.1 \pm 0.1$ & $0.2 \pm 0.1$ & $0.2 \pm 0.1$ & $0.2 \pm 0.1$ & $0.2 \pm 0.0$ & $0.1 \pm 0.1$ \\
\hline & Female & $0.1 \pm 0.1$ & $0.1 \pm 0.3$ & $0.1 \pm 0.1$ & $0.1 \pm 0.1$ & $0.1 \pm 0.1$ & $0.1 \pm 0.0^{\dagger}$ \\
\hline
\end{tabular}

Values are in Mean \pm Standard deviation, ${ }^{*}: \mathrm{mg} / \mathrm{kg},{ }^{\#}:$ Recovery group, ${ }^{* *}$ : blood coagulation(No. 1111, 1409, 2111. except for Prothrombin time and Activated partial thromboplastin time), \#\# : There was nodule with slightly hard egg-shaped(No. 2302), ${ }^{\dagger}:$ significant difference as compared with control( $\left.p<0.05\right)$

the liver (one male), tubular basophilia (two males, one female), medullary mineralization (two females) in the kidney, cortical vacuolation of the adrenal gland (four males), inflammatory cell infiltration of the prostate gland (interstitial, one male), and cysts in the ovary (one female). Some of these lesions were also observed in the control group (i.e., inflammatory cell foci in the liver, tubular basophilia and medullary mineralization in the kidney, cortical vacuolation in the adrenal gland, and inflammatory cell infiltration/interstitial in the prostate gland).

The following histopathological lesions were observed in the high dose recovery group: medullary mineralization in the kidney (one female), cysts in the pituitary gland (pars distalis, one male), and inflammatory cell infiltration in the prostate gland (interstitial, 
Table 6 Blood chemical parameters

\begin{tabular}{|c|c|c|c|c|c|c|c|}
\hline \multirow[t]{2}{*}{ Parameters } & \multirow{2}{*}{$\begin{array}{l}\text { Group(Dose) } \\
\text { Sex/Week }\end{array}$} & \multicolumn{2}{|l|}{$\mathrm{G} 1(0)$} & \multirow{2}{*}{$\begin{array}{l}\text { G2(500) } \\
13 \text { week }\end{array}$} & \multirow{2}{*}{$\begin{array}{l}\text { G3(1000) } \\
\text { 13week }\end{array}$} & \multicolumn{2}{|l|}{ G4(2000) } \\
\hline & & 13week & 17 week $^{\#}$ & & & 13 week & 17 week $^{\#}$ \\
\hline \multirow[t]{2}{*}{ Total protein $(\mathrm{g} / \mathrm{dL})$} & Male & $5.9 \pm 0.4$ & $5.8 \pm 0.3$ & $5.9 \pm 0.3$ & $6.1 \pm 0.3$ & $6.1 \pm 0.1$ & $6.0 \pm 0.3$ \\
\hline & Female & $6.4 \pm 0.5$ & $6.6 \pm 0.5$ & $6.7 \pm 0.5$ & $6.5 \pm 0.5$ & $6.6 \pm 0.4$ & $6.4 \pm 0.3$ \\
\hline \multirow[t]{2}{*}{ Albumin(g/dL) } & Male & $3.8 \pm 0.2$ & $3.9 \pm 0.2$ & $3.8 \pm 0.1$ & $3.9 \pm 0.2$ & $4.0 \pm 0.1$ & $3.9 \pm 0.2$ \\
\hline & Female & $4.2 \pm 0.3$ & $4.4 \pm 0.3$ & $4.4 \pm 0.3$ & $4.3 \pm 0.3$ & $4.4 \pm 0.2$ & $4.2 \pm 0.3$ \\
\hline \multirow[t]{2}{*}{$\mathrm{A} / \mathrm{G}$ ratio } & Male & $1.9 \pm 0.1$ & $2.0 \pm 0.1$ & $1.9 \pm 0.1$ & $1.8 \pm 0.1$ & $1.9 \pm 0.1$ & $1.8 \pm 0.1$ \\
\hline & Female & $2.1 \pm 0.1$ & $2.1 \pm 0.2$ & $1.9 \pm 0.1$ & $2.0 \pm 0.1$ & $2.0 \pm 0.1$ & $1.9 \pm 0.1$ \\
\hline \multirow[t]{2}{*}{ Total bilirubin(mg/dL) } & Male & $0.0 \pm 0.0$ & $0.04 \pm 0.01$ & $0.0 \pm 0.0$ & $0.0 \pm 0.0$ & $0.0 \pm 0.0$ & $0.03 \pm 0.01$ \\
\hline & Female & $0.0 \pm 0.0$ & $0.05 \pm 0.04$ & $0.1 \pm 0.0$ & $0.1 \pm 0.1$ & $0.1 \pm 0.0$ & $0.05 \pm 0.02$ \\
\hline \multirow[t]{2}{*}{ Alkaline phosphatase(U/L) } & Male & $305.3 \pm 66.1$ & $240.4 \pm 55.7$ & $279.8 \pm 50.9$ & $294.6 \pm 48.2$ & $259.4 \pm 50.4$ & $236.8 \pm 17.4$ \\
\hline & Female & $145.8 \pm 46.6$ & $108.0 \pm 51.9$ & $166.2 \pm 73.0$ & $168.9 \pm 70.8$ & $150.6 \pm 44.0$ & $135.8 \pm 40.1$ \\
\hline \multirow[t]{2}{*}{ Aspartate aminotransferase(U/L) } & Male & $97.0 \pm 21.9$ & $130.2 \pm 42.4$ & $102.1 \pm 23.9$ & $107.0 \pm 35.7$ & $105.9 \pm 36.9$ & $85.4 \pm 8.4$ \\
\hline & Female & $91.8 \pm 22.4$ & $123.8 \pm 23.6$ & $105.0 \pm 24.2$ & $87.9 \pm 21.2$ & $87.4 \pm 23.7$ & $113.8 \pm 9.1$ \\
\hline \multirow[t]{2}{*}{ Alanine aminotransferase $(\mathrm{U} / \mathrm{L})$} & Male & $35.1 \pm 7.9$ & $46.0 \pm 15.9$ & $32.5 \pm 5.9$ & $31.0 \pm 5.5$ & $32.2 \pm 5.8$ & $30.8 \pm 6.6$ \\
\hline & Female & $35.8 \pm 10.8$ & $36.4 \pm 7.8$ & $37.7 \pm 10.7$ & $33.0 \pm 12.0$ & $31.4 \pm 9.8$ & $48.8 \pm 14.6$ \\
\hline \multirow[t]{2}{*}{ Creatinine(mg/dL) } & Male & $0.4 \pm 0.0$ & $0.5 \pm 0.0$ & $0.4 \pm 0.0$ & $0.4 \pm 0.0$ & $0.4 \pm 0.0$ & $0.4 \pm 0.1$ \\
\hline & Female & $0.5 \pm 0.1$ & $0.5 \pm 0.0$ & $0.5 \pm 0.0$ & $0.5 \pm 0.1$ & $0.5 \pm 0.1$ & $0.5 \pm 0.0$ \\
\hline \multirow[t]{2}{*}{ Blood urea nitrogen(mg/dL) } & Male & $15.0 \pm 1.4$ & $14.1 \pm 1.4$ & $13.0 \pm 1.8$ & $14.1 \pm 2.7$ & $14.6 \pm 2.1$ & $14.5 \pm 1.2$ \\
\hline & Female & $16.4 \pm 3.0$ & $19.7 \pm 4.7$ & $16.9 \pm 3.6$ & $16.4 \pm 3.0$ & $16.9 \pm 2.0$ & $16.5 \pm 1.2$ \\
\hline \multirow[t]{2}{*}{ Total cholesterol(mg/dL) } & Male & $56.7 \pm 19.7$ & $58.6 \pm 14.4$ & $58.4 \pm 11.8$ & $56.7 \pm 17.7$ & $65.0 \pm 15.2$ & $77.6 \pm 19.2$ \\
\hline & Female & $59.0 \pm 15.3$ & $63.6 \pm 10.4$ & $69.7 \pm 12.3$ & $76.4 \pm 28.2$ & $70.7 \pm 11.2$ & $73.4 \pm 6.9$ \\
\hline \multirow[t]{2}{*}{ Triglycerides(mg/dL) } & Male & $22.0 \pm 12.1$ & $30.2 \pm 22.3$ & $26.3 \pm 5.8$ & $25.2 \pm 8.0$ & $32.8 \pm 14.3$ & $37.0 \pm 11.6$ \\
\hline & Female & $14.2 \pm 4.9$ & $26.2 \pm 14.3$ & $23.1 \pm 10.9$ & $18.6 \pm 7.7$ & $25.4 \pm 9.2^{* *}$ & $18.0 \pm 3.3$ \\
\hline \multirow[t]{2}{*}{ Glucose(mg/dL) } & Male & $153.5 \pm 18.6$ & $174.4 \pm 18.2$ & $160.6 \pm 25.1$ & $151.1 \pm 17.6$ & $153.0 \pm 21.2$ & $191.4 \pm 37.0$ \\
\hline & Female & $144.6 \pm 14.4$ & $162.8 \pm 17.6$ & $158.4 \pm 11.7$ & $168.0 \pm 32.6$ & $156.3 \pm 12.8$ & $162.0 \pm 18.7$ \\
\hline \multirow[t]{2}{*}{ Calcium(mg/dL) } & Male & $9.3 \pm 0.4$ & $8.8 \pm 0.1$ & $9.3 \pm 0.3$ & $9.3 \pm 0.3$ & $9.6 \pm 0.2$ & $8.9 \pm 0.1$ \\
\hline & Female & $9.3 \pm 0.4$ & $9.0 \pm 0.3$ & $9.5 \pm 0.3$ & $9.4 \pm 0.4$ & $9.4 \pm 0.3$ & $8.9 \pm 0.2$ \\
\hline \multirow[t]{2}{*}{ Inorganic phosphorus(mg/dL) } & Male & $6.1 \pm 0.6$ & $5.1 \pm 0.3$ & $5.9 \pm 0.4$ & $5.7 \pm 0.6$ & $5.9 \pm 0.4$ & $5.0 \pm 0.4$ \\
\hline & Female & $4.5 \pm 1.0$ & $3.7 \pm 0.9$ & $4.9 \pm 1.1$ & $4.7 \pm 1.0$ & $4.7 \pm 1.0$ & $3.3 \pm 0.5$ \\
\hline \multirow[t]{2}{*}{ Creatine kinase $(\mathrm{U} / \mathrm{L})$} & Male & $305.8 \pm 184.8$ & $392.8 \pm 184.1$ & $402.7 \pm 266.3$ & $461.3 \pm 412.7$ & $414.2 \pm 408.6$ & $262.0 \pm 112.5$ \\
\hline & Female & $206.5 \pm 135.2$ & $525.8 \pm 260.9$ & $292.1 \pm 267.7$ & $192.0 \pm 80.9$ & $222.7 \pm 139.0$ & $384.8 \pm 260.2$ \\
\hline \multirow[t]{2}{*}{ Sodium(mmol/L) } & Male & $145.7 \pm 0.9$ & $146.3 \pm 1.0$ & $145.7 \pm 0.6$ & $146.1 \pm 0.8$ & $146.7 \pm 0.6^{* *}$ & $145.9 \pm 1.4$ \\
\hline & Female & $144.4 \pm 1.3$ & $145.3 \pm 0.8$ & $144.8 \pm 0.9$ & $144.9 \pm 0.0$ & $143.8 \pm 1.0$ & $144.8 \pm 0.4$ \\
\hline \multirow[t]{2}{*}{ Potassium(mmol/L) } & Male & $4.7 \pm 0.2$ & $4.5 \pm 0.3$ & $4.7 \pm 0.3$ & $4.5 \pm 0.4$ & $4.6 \pm 0.4$ & $4.5 \pm 0.5$ \\
\hline & Female & $3.9 \pm 0.2$ & $4.31 \pm 0.35$ & $4.2 \pm 0.6$ & $4.2 \pm 0.3$ & $4.1 \pm 0.2$ & $4.52 \pm 0.23$ \\
\hline \multirow[t]{2}{*}{ Chloride(mmol/L) } & Male & $106.9 \pm 1.7$ & $106.6 \pm 1.0$ & $105.8 \pm 0.9$ & $106.4 \pm 1.0$ & $106.0 \pm 1.4$ & $106.4 \pm 2.1$ \\
\hline & Female & $107.2 \pm 1.4$ & $107.8 \pm 1.0$ & $106.8 \pm 2.1$ & $106.2 \pm 1.6$ & $106.0 \pm 1.9$ & $108.1 \pm 1.1$ \\
\hline
\end{tabular}

Values are in Mean \pm Standard deviation, ${ }^{*}: \mathrm{mg} / \mathrm{kg},{ }^{*}:$ Recovery group, ${ }^{* *}:$ significant difference as compared with control $(p<0.05)$

one male). Similar to the treatment groups, some of these lesions were observed in the control group (i.e., medullary mineralization in the kidney and cysts in the pars distalis of the pituitary gland).

Moreover, histopathological lesions were also observed in organs with gross lesions. These include tubular atrophy in the testis, oligospermia in the epididymis (reduced left testis in the control group, Fig. 4), abscess (yellowish nodule on the prostate gland of animals administered the middle dose, Fig. 5), and basal cell carcinoma (cysts and mass in the right submandibular region of animals administered the middle dose, Fig. 6). Lung metastasis was also observed following basal cell carcinoma (Fig. 7). The histopathological lesions are shown in Table 7. 


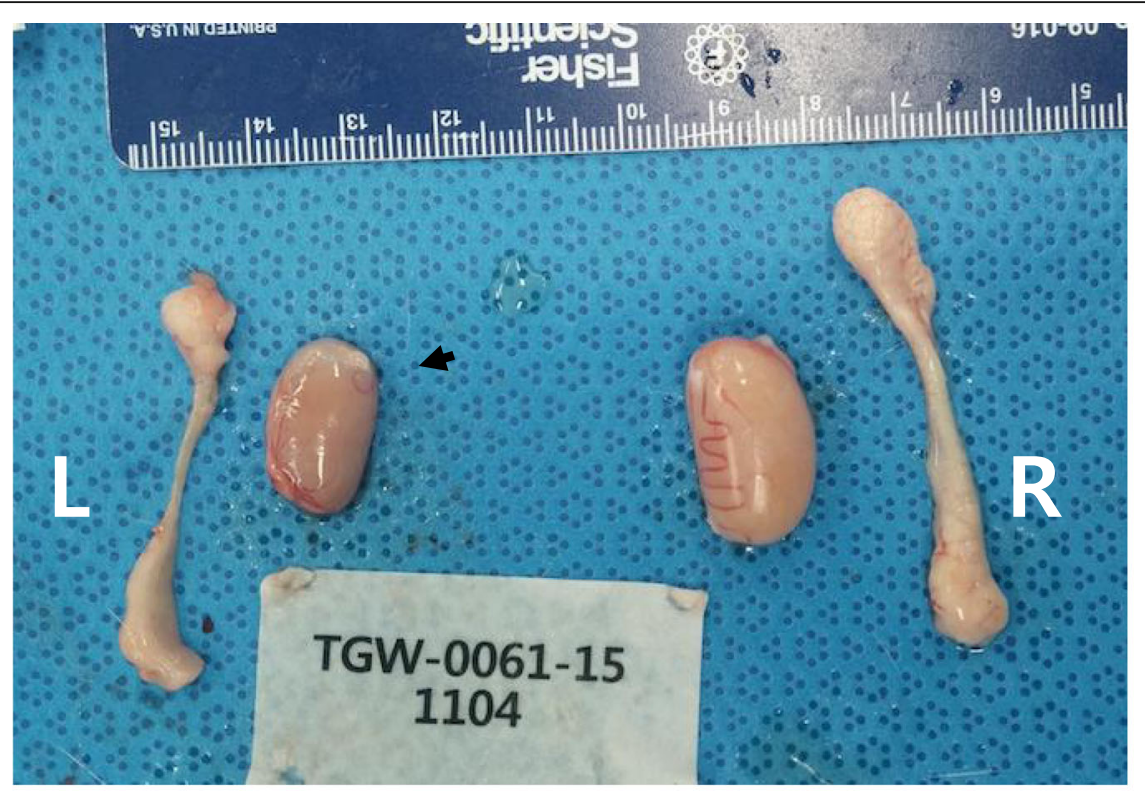

(A)

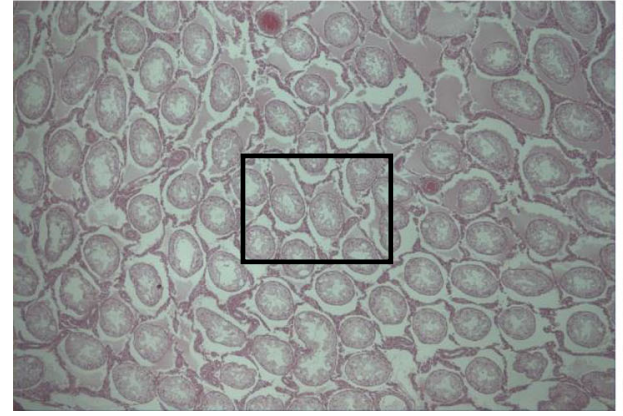

$H \& E, 50 X$

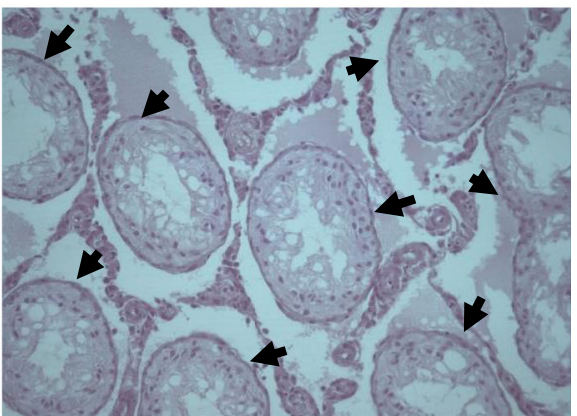

$H \& E, 200 X$

(B)

Fig. 4 Reduced left testis in male G1 (control group; rat number 1104) (a) Necropsy finding, (b) Tubular atrophy; H\&E 50X, 200X

\section{Discussion}

Osteoarthritis is emerging as an important issue resulting from the loss of cartilage associated with the shape of bones, such as osteophytes and subchondral bone sclerosis. It is caused by population aging, an increase in obesity, and a lack of definitive treatment [11-13]. Symptoms of osteoarthritis include progressive asymmetrical pain, joint stiffness, and restricted joint movement, which can hinder the performance of daily activities [14-16].

ChondroT is a new complex herbal medication developed for the treatment of osteoarthritis and its efficacy and safety have been demonstrated in several studies [4-8]. Although the safety of this herbal complex has been confirmed through animal studies, we sought to carry out the present study with additional doses and perform a rigorous toxicity study that could be translated to human clinical trials.

Herein, we aimed to evaluate the systemic toxicity response when ChondroT, the test substance, is administered via the oral route for 13 weeks, and determine its NOAEL. This 13-week repeated oral administration study included doses of 500, 1000, and $2000 \mathrm{mg} / \mathrm{kg}$ body weight.

During the test period, there were no treatmentrelated moribund or dead animals of any sex in the treatment groups. In addition, there were no significant changes in food consumption, urinalysis, and ophthalmological examination. Clinical signs included loss of fur in one female administered the $1000 \mathrm{mg} / \mathrm{kg}$ dose; however, this was not dose-dependent and was only observed in one animal. Although salivation was observed 


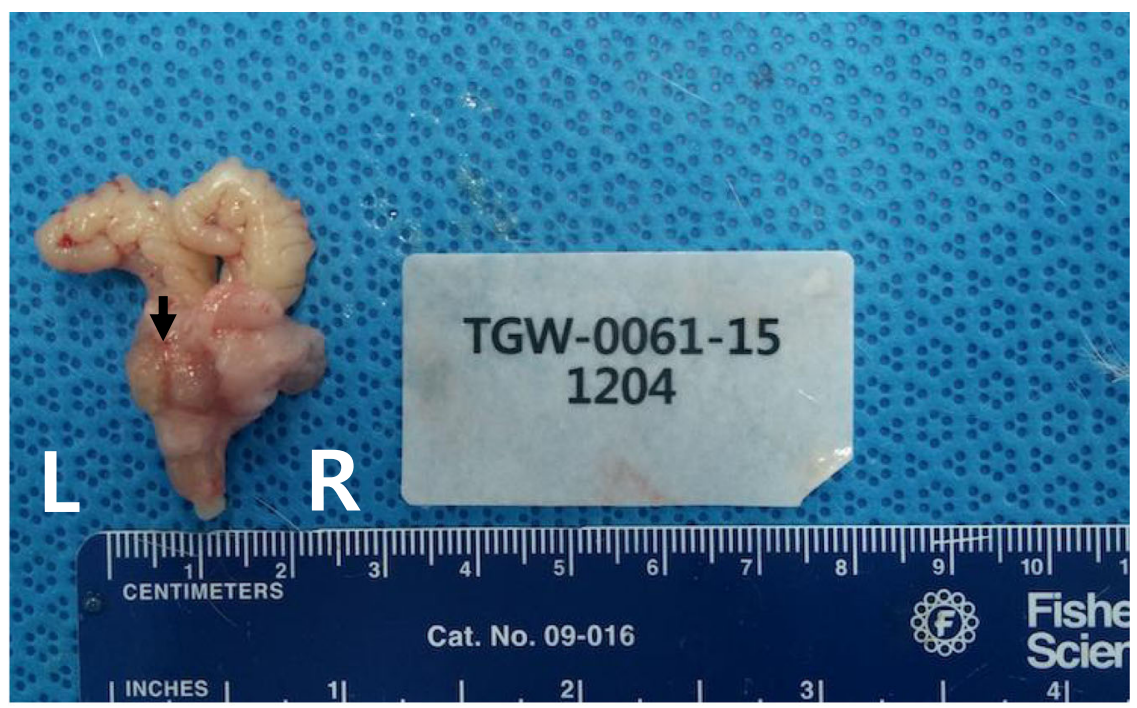

(A)

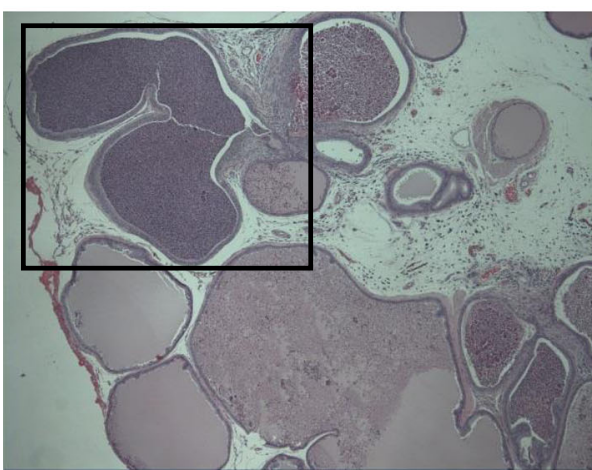

$H \& E, 50 X$

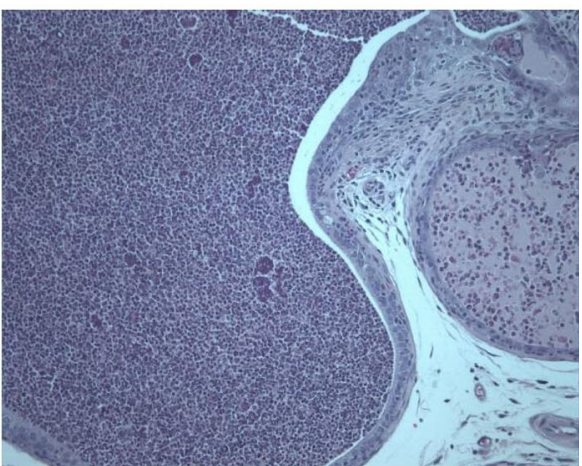

$H \& E, 200 X$

(B)

Fig. 5 Yellowish nodules on the prostate gland of male G2 (low dose group; rat number 1204) (a) Necropsy finding, (b) Abscess; H\&E 50X, 200X

in some of the animals administered $2000 \mathrm{mg} / \mathrm{kg}$ of the test substance, continuous and transient or intermittent observations were not found for both sexes. Hence, these signs did not represent treatment-related toxicological effects and were considered to be incidental signs.

Body weight is a parameter affected by adverse effects exhibited by drugs and chemicals [17]. The increasing tendency of body weight in males administered the 2000 $\mathrm{mg} / \mathrm{kg}$ dose was considered to be a treatment-related effect and not a toxicological effect. This was due to the changes observed in organ weight, hematological biochemistry parameters, and histopathological examination. A further study may however be needed to confirm whether or not toxic effects have an impact on body weight (e.g., chronic study).

There were no significant differences among the treatment groups based on the hematological analysis.
Although significant differences were found when the $2000 \mathrm{mg} / \mathrm{kg}$ dose was administered, no histological lesions, organ weight changes, and gross findings were observed in the relevant organs. This indicates a normal biological variation and the lack of a treatment-related effect.

Based on the necropsy findings, there were no treatment-related effects for both sexes in the treatment groups. Nonetheless, histopathological examination revealed gross findings such as tubular atrophy with oligospermia of the epididymis and abscess in the control (reduced left testis) and treatment groups (nodule on the prostate gland at $500 \mathrm{mg} / \mathrm{kg}$ ), respectively.

Previously, the incidence of spontaneous testicular atrophy in the testis of SD rats was reported to be $0.2 \%$, $7.9 \%$, and $10 \%$ at 4,13 , and 26 weeks, respectively. In addition, the epididymis with testicular atrophy has been 


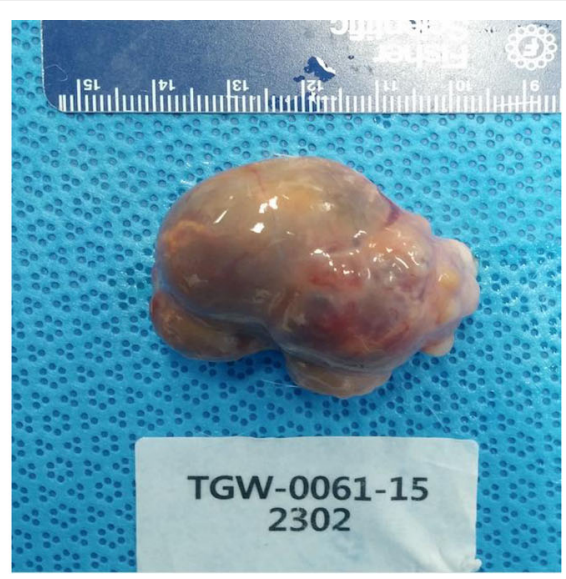

(A)

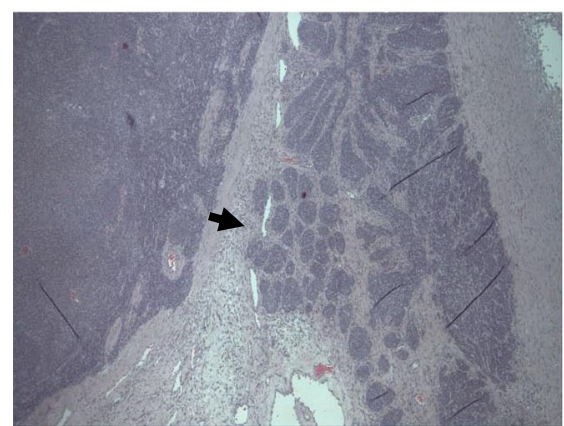

(B) $H \& E, 50 X$

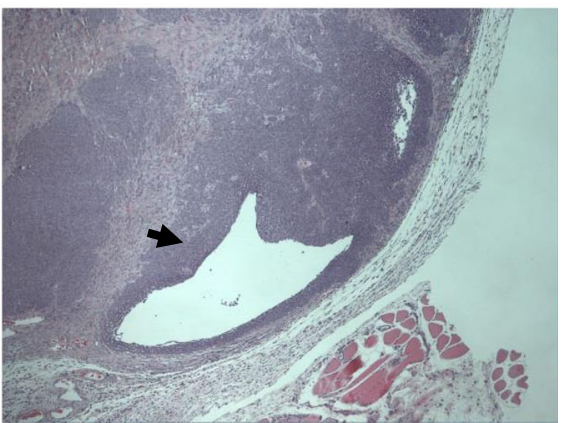

(C) H\&E, 50X

Fig. 6 Cysts and mass in the submandibular region of female G3 (middle dose group; rat number 2302) (a) Necropsy finding (b) Basal cell carcinoma with aggregates of basaloid cells, H\&E 50X (C) Basal cell carcinoma with cystic structure, H\&E 50X

reported to show low sperm density (oligospermia) [18]. Therefore, the observed lesion in this study may have been an aberration based on the lesion observed in the control group.

Male accessory sex glands are frequently observed as a site of inflammatory lesions and may appear as large abscesses or small suppurative lesions. Prostatitis is commonly observed in older rats but has been observed in young adult rats used in toxicity studies, especially in the dorsolateral prostate gland [19]. Therefore, the gross finding for the prostate gland in animals in the middle dose group might not be a treatment-related effect due

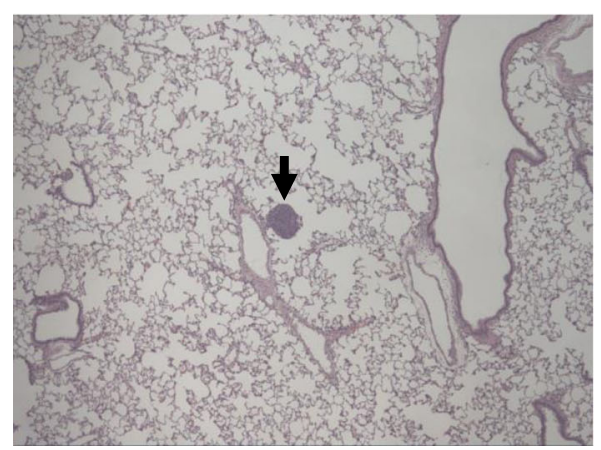

(A) $H \& E, 50 X$

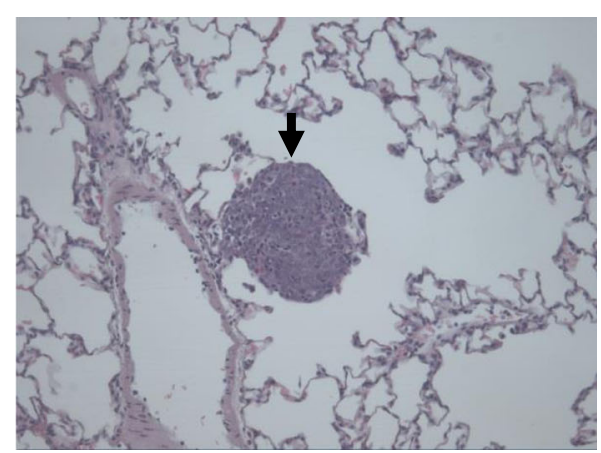

(B) H\&E, 200X

Fig. 7 Basal cell carcinoma metastasis in the lung (tumor cell nodule) of female G3 (middle dose group; rat number 2302) (a) H\&E 50X (b) H\&E 200X 
Table 7 Histopathological findings

\begin{tabular}{|c|c|c|c|c|c|c|c|c|c|}
\hline \multirow[t]{3}{*}{ Organs } & \multirow[t]{3}{*}{ Histopathological findings } & \multicolumn{4}{|c|}{$\mathrm{G} 1(0)^{*}$} & \multicolumn{4}{|c|}{$\mathrm{G} 4(2000)^{*}$} \\
\hline & & \multicolumn{2}{|c|}{13 week } & \multicolumn{2}{|c|}{17 week $^{\#}$} & \multicolumn{2}{|c|}{13 week } & \multicolumn{2}{|c|}{17 week $^{\#}$} \\
\hline & & $\mathrm{M}$ & $\mathrm{F}$ & $\bar{M}$ & $\mathrm{~F}$ & $\mathrm{M}$ & $\mathrm{F}$ & $\bar{M}$ & $\mathrm{~F}$ \\
\hline \multirow[t]{2}{*}{ Liver } & $N A D^{* *}$ & 8 & 9 & 4 & 5 & 9 & 10 & 5 & 5 \\
\hline & Inflammatory cell foci - Minimal, multifocal & 2 & 1 & 1 & 0 & 1 & 0 & 0 & 0 \\
\hline \multirow[t]{6}{*}{ Kidney } & NAD & 9 & 8 & 4 & 2 & 8 & 7 & 5 & 4 \\
\hline & Tubular basophilia - Minimal, multifocal & 1 & 2 & 1 & 0 & 1 & 1 & 0 & 0 \\
\hline & Tubular casts - present & 1 & 0 & 0 & 0 & 0 & 0 & 0 & 0 \\
\hline & Medullary mineralization - Minimal, multifocal & 0 & 1 & 0 & 2 & 0 & 2 & 0 & 1 \\
\hline & Focal nephropathy - Slight, focal & 0 & 0 & 1 & 0 & 0 & 0 & 0 & 0 \\
\hline & Inflammatory cell infiltration, interstitial - Minimal, Multifocal & 0 & 0 & 0 & 1 & 0 & 0 & 0 & 0 \\
\hline \multirow[t]{2}{*}{ Adrenal Gland } & NAD & 7 & 10 & 5 & 5 & 6 & 10 & 5 & 5 \\
\hline & Cortical vacuolation - Minimal, multifocal & 3 & 0 & 0 & 0 & 4 & 0 & 0 & 0 \\
\hline Heart & NAD & 10 & 10 & 5 & 5 & 10 & 10 & 5 & 5 \\
\hline \multirow{2}{*}{$\begin{array}{l}\text { Lung } \\
\text { (bronchus) }\end{array}$} & NAD & 10 & 10 & 4 & 5 & 10 & 10 & 5 & 5 \\
\hline & Inflammatory cell infiltration, perivascular - Minimal, multifocal & 0 & 0 & 1 & 0 & 0 & 0 & 0 & 0 \\
\hline \multirow[t]{2}{*}{ Brain $\#$} & NAD & 10 & 10 & 4 & 5 & 10 & 10 & 4 & 5 \\
\hline & Pituitary: Cyst, pars distalis - Present & 0 & 0 & 1 & 0 & 0 & 0 & 1 & 0 \\
\hline Spinal Cord & NAD & 10 & 10 & 5 & 5 & 10 & 10 & 5 & 5 \\
\hline Spleen & NAD & 10 & 10 & 5 & 5 & 10 & 10 & 5 & 5 \\
\hline Seminal Vesicle & NAD & 10 & - & 5 & - & 10 & - & 5 & - \\
\hline \multirow[t]{2}{*}{ Prostate gland } & NAD & 9 & - & 5 & - & 9 & - & 4 & - \\
\hline & Inflammatory cell infiltration, interstitial - Minimal, Multifocal & 1 & - & 0 & - & 1 & - & 1 & - \\
\hline \multirow[t]{2}{*}{ Testis } & NAD & 9 & - & 5 & - & 10 & - & 5 & - \\
\hline & Tubular atrophy in left testis - Severe, diffuse & 1 & - & 0 & - & 0 & - & 0 & - \\
\hline \multirow[t]{2}{*}{ Epididymis } & NAD & 9 & - & 5 & - & 10 & - & 5 & - \\
\hline & Oligospermia in left epididymis - Severe, diffuse & 1 & - & 0 & - & 0 & - & 0 & - \\
\hline \multirow[t]{3}{*}{ Ovary } & NAD & - & 9 & - & 4 & - & 9 & - & 5 \\
\hline & Cyst - Present & - & 1 & - & 1 & - & 0 & - & 0 \\
\hline & Cysts - Present & - & 0 & - & 0 & - & 1 & - & 0 \\
\hline Uterus & NAD & - & 10 & - & 5 & - & 10 & - & 5 \\
\hline Vagina & NAD & - & 10 & - & 5 & - & 10 & - & 5 \\
\hline Trachea & NAD & 10 & 10 & 5 & 5 & 10 & 10 & 5 & 5 \\
\hline Esophagus & NAD & 10 & 10 & 5 & 5 & 10 & 10 & 5 & 5 \\
\hline \multirow[t]{2}{*}{ Thymus } & NAD & 10 & 10 & 5 & 4 & 10 & 10 & 5 & 5 \\
\hline & Cysts - Present & 0 & 0 & 0 & 1 & 0 & 0 & 0 & 0 \\
\hline Thyroid gland & NAD & 10 & 10 & 5 & 5 & 10 & 10 & 5 & 5 \\
\hline Tongue & NAD & 10 & 10 & 5 & 5 & 10 & 10 & 5 & 5 \\
\hline Stomach & NAD & 10 & 10 & 5 & 5 & 10 & 10 & 5 & 5 \\
\hline Urinary bladder & NAD & 10 & 10 & 5 & 5 & 10 & 10 & 5 & 5 \\
\hline Intestine ${ }^{\dagger}$ & NAD & 10 & 10 & 5 & 5 & 10 & 10 & 5 & 5 \\
\hline Eye & NAD & 10 & 10 & 5 & 5 & 10 & 10 & 5 & 5 \\
\hline Harderian gland & NAD & 10 & 10 & 5 & 5 & 10 & 10 & 5 & 5 \\
\hline Skin & NAD & 10 & 10 & 5 & 5 & 10 & 10 & 5 & 5 \\
\hline Mammary gland & NAD & 10 & 10 & 5 & 5 & 10 & 10 & 5 & 5 \\
\hline
\end{tabular}


Table 7 Histopathological findings (Continued)

\begin{tabular}{|c|c|c|c|c|c|c|c|c|c|}
\hline \multirow[t]{3}{*}{ Organs } & \multirow[t]{3}{*}{ Histopathological findings } & \multicolumn{4}{|c|}{$\mathrm{G} 1(0)^{*}$} & \multicolumn{4}{|c|}{$\mathrm{G} 4(2000)^{*}$} \\
\hline & & \multicolumn{2}{|c|}{13 week } & \multicolumn{2}{|c|}{ 17week ${ }^{\#}$} & \multicolumn{2}{|c|}{ 13week } & \multicolumn{2}{|c|}{17 week $^{\#}$} \\
\hline & & $\bar{M}$ & $\mathrm{~F}$ & $\bar{M}$ & $\mathrm{~F}$ & M & $\mathrm{F}$ & $M$ & $\mathrm{~F}$ \\
\hline Submandibular gland & NAD & 10 & 10 & 5 & 5 & 10 & 10 & 5 & 5 \\
\hline Skeletal muscle & NAD & 10 & 10 & 5 & 5 & 10 & 10 & 5 & 5 \\
\hline Sciatic nerve & NAD & 10 & 10 & 5 & 5 & 10 & 10 & 5 & 5 \\
\hline \multirow[t]{2}{*}{ Pancreas } & NAD & 10 & 10 & 4 & 5 & 10 & 10 & 5 & 5 \\
\hline & Islet fibrosis - Minimal, multifocal & 0 & 0 & 1 & 0 & 0 & 0 & 0 & 0 \\
\hline Sternum & NAD & 10 & 10 & 5 & 5 & 10 & 10 & 5 & 5 \\
\hline Femur & NAD & 10 & 10 & 5 & 5 & 10 & 10 & 5 & 5 \\
\hline
\end{tabular}

${ }^{*}:$ Dose $(\mathrm{mg} / \mathrm{kg}),{ }^{\#}:$ Recovery group ${ }^{* *}:$ No abnormality detected, ${ }^{\# \#}:$ Cerebrum, Cerebellum, Pituitary, ${ }^{\dagger}:$ Both small and large intestine

to the non-existent dose relationship and the frequency of necropsy.

Organ weight could be a meaningful indicator of treatment-related changes with or without corresponding histopathological examination in repeated toxicity studies [20]. In this study, organ weight changes lacking a dose relationship were observed in some organs. In addition, a relationship between absolute weight and relative weight was not found. Additionally, treatmentrelated histological findings were not observed. Therefore, changes were considered to be normal biological variation.

In the histopathological examination, the lesions observed in animals administered the $2000 \mathrm{mg} / \mathrm{kg}$ were spontaneous incidence lesions, such as inflammatory cell foci (liver), tubular basophilia/medullary mineralization (kidney), cortical vacuolation (adrenal gland), inflammatory cell infiltration (prostate gland), and cysts (ovary, pars distalis of pituitary gland), which are common in repeated toxicity studies. These lesions were also observed in the control group but their frequency and grade were minor [19]. In addition, these lesions might have been background lesions and not a treatment-related effect.

Spontaneous basal cell carcinoma is very rare in rats, with an incidence rate of only $0.14 \%$ in aged animals. It is also rarely observed in young SD rats. Spontaneous basal cell carcinoma was reported recently in a subcutaneous mass found in the left inguinal region of a young (7-week) SD rat [21, 22]. In the present study, this lesion was only observed in one animal in the middle dose group and did not result in a dose-dependent response. Therefore, it was considered to be a treatment-related effect and spontaneous lesion.

Sub-chronic exposure of rats to ChondroT did not result in treatment-related changes at doses up to 2000 $\mathrm{mg} / \mathrm{kg}$. This result suggests that ChondroT might be safe and is in agreement with the human equivalent dose (HED) of $324.32 \mathrm{mg} / \mathrm{kg} /$ day; animal dose $(\mathrm{mg} / \mathrm{kg}) \times$ (rat $K_{\mathrm{m}}$ factor '6'/Human adult $60 \mathrm{~kg} \mathrm{~K}_{\mathrm{m}}$ factor '37')] using body surface area (BSA, $\mathrm{mg} / \mathrm{m}^{2}$ ) for initial clinical trials involving healthy adult volunteers [23, 24].

In conclusion, the results of the present 13-week repeated oral dose toxicity study demonstrated that administering ChondroT did not adversely affect most of the toxicological factors in male and female SD rats. With the experimental conditions adopted in the present study, we found that the NOAEL of ChondroT was 2000 $\mathrm{mg} / \mathrm{kg} /$ day and a target organ was not indicated.

\section{Conclusions}

In previous studies, ChondroT was demonstrated to be effective in arthritis via its chondroprotective and antiinflammatory mechanisms. Based on the results of this study, we found that its NOAEL was $2000 \mathrm{mg} / \mathrm{kg}$, which reveals that ChondroT does not exhibit toxicity under the conditions employed in the study. As a new complex herbal medication composed of five plants, ChondroT can be used safely at its NOAEL

\section{Abbreviations \\ GHJTY: Ganghwaljetongyeum; OA: Osteoarthritis; CFA: Complete Freund's adjuvant; TNF-a: Tumor necrosis factor-a; IL-1 $\beta$ : Interleukin-1 $\beta$; AST: Aspartate aminotransferase; ALT: Alanine transaminase; BUN: Blood urea nitrogen; NOAEL: no observed adverse effect level; SD rat: Sprague-Dawley rat; KTR: Korea Testing \& Research Institute; S.D: standard deviation; MFDS: Ministry of Food and Drug Safety; AVMA: American Veterinary Medical Association; IACUC: Institutional Animal Care and Use Committee; HPLC: high-performance liquid chromatography; PDA: photo-diode array}

\section{Acknowledgments}

Not applicable.

\section{Authors' contributions}

JJ, JK, CSS, and MP carried out all experiments, collected the data, and prepared the manuscript; KB, CN, YK, and CC helped to draft the manuscript and performed the critical revision for important intellectual content; SJK supervised the study as the project leader and helped to draft the manuscript. All authors read and approved the final manuscript.

Funding

This study was supported by a grant of the Korea Healthcare technology R\&D Project, Ministry for Health \& Welfare Affairs, Republic of Korea (grant number: HI17C0911). The funding body provided financial support and had 
no role in the design of the study, data collection, data analysis and writing the manuscript.

\section{Availability of data and materials}

The datasets used and/or analyzed in the current study are available from the corresponding author on reasonable request.

\section{Ethics approval and consent to participate}

This study protocol was reviewed and approved (IAC2015-0797) by the Institutional Animal Care and Use Committee (IACUC) of KTR Hwasun based on the Animal Protection Act [Enforcement Date: 2015-01-20; No. 13023(2015-01-20, partial revision)] and the Laboratory Animal Act [Enforcement Date: 2013-07-30; No. 11987(2013-07-30, partial revision)]. This study was conducted in accordance with the guideline for toxicity testing of pharmaceuticals, MFDS (Notification No. 2014-136, 2014-07-30).

\section{Consent for publication}

Not applicable.

\section{Competing interests}

The authors declare that they have no competing interests.

\section{Author details}

${ }^{1}$ Yeongam Public Health Center, 39 Orijeong-gil, Yeongam, 58421 Jeollanam-do, Republic of Korea. ${ }^{2}$ Department of Korean Medical Rehabilitation, Kwangju Korean Medicine Hospital of Dongshin University, 313 Baengnyeondae-ro, Mokpo, 58665 Jeollanam-do, Republic of Korea. ${ }^{3}$ College of Korean Medicine, Dongshin University, 185 Geonjae-ro, Naju, 58245 Jeollanam-do, Republic of Korea. ${ }^{4}$ Healthcare Research Institute, Korea Testing and Research Institute (KTR), 12-63 Sandan-gil, Hwasun, 58141 Jeollanam-do, Republic of Korea. ${ }^{5}$ College of Pharmacy, Chonnam National University, 77 Yongbong-ro, Buk-gu, Gwangju 61186, Republic of Korea. ${ }^{6}$ Herbal Medicine Research Division, Korea Institute of Oriental Medicine, 1672 Yuseong-daero, Yuseong-gu, Daejeon 34054, Republic of Korea.

Received: 26 February 2019 Accepted: 26 November 2019 Published online: 12 December 2019

\section{References}

1. Kim YH, Lee JH. CheongKangEuiGam. Seoul: Seongbosa; 2001. p. 315.

2. Jeoung BR, Lee KD, Na CS, Kim YE, Kim B, Kim YR. Ganghwaljetongyeum, an anti-arthritic remedy, attenuates synoviocyte proliferation and reduces the production of proinflammatory mediators in macrophages: the therapeutic effect of GHJTY on rheumatoid arthritis. BMC Complement Altern Med. 2013:13:47-52

3. Choi W, Choi CH, Kim YR, Kim SJ, Na CS, Lee H. HerDing: herb recommendation system to treat diseases using genes and chemicals. Database-Oxford. 2016;2016:baw011. https://doi.org/10.1093/database/ baw011.

4. Kim W, Park S, Choi C, Kim YR, Park I, Seo C, et al. Evaluation of AntiInflammatory Potential of the New Ganghwaljetongyeum on AdjuvantInduced Inflammatory Arthritis in Rats. Evid Based Complement Alternat Med. 2016;2016:1-10.

5. Bae KJ, Jeong JW, Choi CH, Won JY, Kim TG, Kim YR, et al. Antiosteoarthritic Effects of ChondroT in a Rat Model of Monosodium lodoacetate-Induced Osteoarthritis. Evid Based Complement Alternat Med. 2018;2018:1-11.

6. Jeong JW, Bae KJ, Kim SG, Kwak DW, Moon Y-J, Choi CH, et al. Antiosteoarthritic effects of ChondroT in a rat model of collagenase-induced osteoarthritis. BMC Complement Altern Med. 2018;18:131-40.

7. Park JU, Kim SJ, Na CS, Choi C, Seo CS, Son JK, et al. Chondroprotective and anti-inflammatory effects of ChondroT, a new complex herbal medication. BMC Complement Altern Med. 2016;16:213-23.

8. Oh DR, Kim JR, Choi CY, Choi C hun, Na C su, Kang BY, et al. Effects of ChondroT on potassium Oxonate-induced Hyperuricemic mice: downregulation of xanthine oxidase and urate transporter 1. BMC Complement Altern Med. 2019;19:10-17.

9. Lee S, Kim SJ. Efficacy and safety of ChondroT on knee-osteoarthritis: Protocol for a 8-week, randomized, double-blind, placebo-controlled, multicenter therapeutic exploratory clinical trial. Medicine Baltimore. 2018; 97:e0170.
10. Lim YH, Jeong JW, Kim SG, Kim JH, Kim SJ. DRF and Single Dose Oral Toxicity Study of ChondroT in Rat. J Korean Med Rehabil. 2018;28:61-72.

11. Dequeker J, Luyten FP. The history of osteoarthritis-osteoarthrosis. Ann Rheum Dis. 2008:67:5-10.

12. Neogi T. Clinical significance of bone changes in osteoarthritis. Ther Adv Musculoskel Dis. 2012:4:259-67.

13. Conaghan PG, Vanharanta H, Dieppe PA. Is progressive osteoarthritis an atheromatous vascular disease? Ann Rheum Dis. 2005;64:1539-41.

14. Altman RD. Criteria for classification of clinical osteoarthritis. J Rheumatol Suppl. 1991;27:10-2.

15. Bijlsma JW, Berenbaum F, Lafeber FP. Osteoarthritis: an update with relevance for clinical practice. Lancet. 2011;377:2115-26.

16. Zhang W, Doherty M, Peat G, Bierma-Zeinstra MA, Arden NK, Bresnihan B, et al. EULAR evidence-based recommendations for the diagnosis of knee osteoarthritis. Ann Rheum Dis. 2010;69:483-9.

17. Santos SR, Rangel ET, Lima JCS, Silva RM, Lopes L, Noldin VF, et al. Toxicological and phytochemical studies of Aspidosperma subincanum Mart. stem bark Guatambu. Pharmazie. 2009;64:836-9.

18. Son HY, Kim YB, Ha CS, Kang BH. Histopathological observation of spontaneous testicular atrophy in Sprague-Dawley rat. Korean J Vet Pathol. 1998;2:47-51.

19. Boorman GA. Pathology of the Fischer rat: reference and atlas. San Diego: Academic Press; 1990.

20. Pritam SS, James AP, Jerry FH, Chirukandath G. Toxicologic Pathology: Nonclinical Safety Assessment. Boca Raton: CRC Press; 2013. p. 77-96.

21. Lee HY, Na YR, Seok SH, Baek MW, Kim DJ, Park SH, et al. Spontaneous Basal Cell Carcinoma in a 7-Week-Old Sprague-Dawley Rat. Vet Pathol. 2010;47: 137-9.

22. Zwicker GM, Eyster RC, Sells DM, Gass JH. Spontaneous Skin Neoplasms in Aged Sprague-Dawley Rats. Toxicol Pathol. 1992;20:327-40.

23. Shannon RS, Minakshi N, Nihal A. Dose translation from animal to human studies revisited. FASEB J. 2008;22:659-61.

24. Choi J, Ryu SJ, Kim KJ, Kim HM, Chung HC, Lee BY. Single, 14-Day, and 13Week Repeated Dose Toxicity Studies of Daily Oral Gelidium elegans Extract Administration to Rats. Molecules. 2018:23:217-35.

\section{Publisher's Note}

Springer Nature remains neutral with regard to jurisdictional claims in published maps and institutional affiliations.
Ready to submit your research? Choose BMC and benefit from:

- fast, convenient online submission

- thorough peer review by experienced researchers in your field

- rapid publication on acceptance

- support for research data, including large and complex data types

- gold Open Access which fosters wider collaboration and increased citations

- maximum visibility for your research: over $100 \mathrm{M}$ website views per year

At $\mathrm{BMC}$, research is always in progress.

Learn more biomedcentral.com/submissions 